\title{
四唑类化合物的合成及应用研究新进展
}

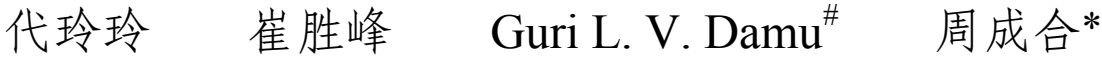 \\ (西南大学化学化工学院 重庆 400715)
}

\begin{abstract}
摘要 四唑是一种重要的五元芳杂环, 具有多氮富电子的平面结构特征. 这种特殊的结构使得四唑类化合物作为药 物、炸药、功能材料等在医学、农学、材料科学等众多领域具有广泛的应用前景. 相关研究十分活跃, 已取得了许多 重要进展. 结合作者唑类方面的研究, 参考国内外近五年文献, 系统地综述了四唑类化合物的合成及其在医药、农药、 材料等领域的应用研究新近况.
\end{abstract}

关键词＼cjkstart四唑；抗高血压；抗菌；抗病毒；除草剂；含能材料；催化剂

\section{Recent Advances in the Synthesis and Application of Tetrazoles}

\author{
Dai, Lingling Cui, Shengfeng $\quad$ Damu, Guri L. V." Zhou, Chenghe* \\ (School of Chemistry and Chemical Engineering, Southwest University, Chongqing 400715)
}

\begin{abstract}
Tetrazole is an important five-membered aromatic heterocycle with poly-nitrogen electron-rich planar structural feature. This unique structure endows tetrazole derivatives as drugs, explosives, functional materials etc. to exhibit wide potential applications in medicinal, agrochemical, material science and so on. Relevant researches have been becoming active and some important achievements have been made. Based our work on azoles and referring to other literature in recent 5 years, this review systematically summarized the recent advances in the synthesis of tetrazole compounds and their application researches as medicinal drugs, agrochemicals and materials.
\end{abstract}

Keywords tetrazole; antihypertensive; antibacterial; antiviral; herbicide; energetic materials; catalyst

氮唑类杂环化合物是一类结构特殊的化合物，具有 许多独特的性能，在众多领域表现出巨大的应用潜力，

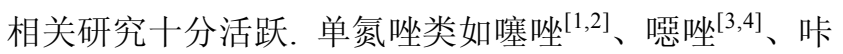
唑 ${ }^{[5,6]}$ 和双氮唑类如咪唑 ${ }^{[7 \sim 9]}$ 、苯并咪唑 ${ }^{[10 ~ 12]}$ 以及三氮唑

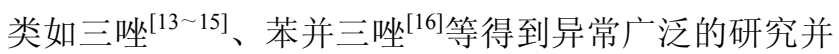
且许多已经应用于医药、农业等众多领域, 而有关四氮 唑类化合物的应用研究情况至今没有文献对其进行完 整而系统报道. 含四个氮原子的四唑作为氮唑类化合物 的一员, 其环骨架为平面结构, 多氮富电子的共轭体系 赋予了四唑类化合物既能给出电子又能接受电子特性, 这使其可发生多种非共价键相互作用，如易形成氢键、 与金属离子配位、 $\pi-\pi$ 堆积、静电作用等, 因而四唑类 化合物表现出许多特殊的性能, 在医药、农药、材料科
学、化学化工等众多领域显示出宽广的应用潜力和较大 的开发价值. 有关四唑类化合物的合成及其应用的研究 工作较为活跃, 已经取得杰出成果. 在医学领域, 四唑 类化合物可与生物体内多种酶和受体相互作用而呈现 出广泛的生物活性, 目前已有较多四唑类化合物用于临 床, 如沙坦类抗高血压药物奥美沙坦酯 $(\mathbf{1}$, Olmesartan Medoxomil)和坦坎地沙坦酯(2, Candesartan Cilexetil)、抗 生素药物头狍雷特 (3, Ceforanide)和头狍哌酮 $\mathbf{4}$, Cefoperazone)等均具有较好临床治疗效果. 与此同时, 四唑 环可作为三唑、咪唑、酰胺以及羧基的生物电子等排体, 在改善化合物的生物活性及药代动力学方面起重要作 用, 被广泛用于药物设计与开发; 在农业领域, 四唑类 化合物作为农药的研发十分活跃, 特别是在除草和植物

\footnotetext{
* E-mail: zhouch@swu.edu.cn; Tel./Fax:+86-23-68254967.

Received August 31, 2012; revised November 5, 2012; accepted November 14, 2012.

${ }^{*}$ Postdoctoral fellow from Indian Institute of Chemical Technology (IICT), Hyderabad-500 607, India

Project supported by the National Natural Science Foundation of China (No. 21172181), the Research Fellowship for International Young Scientists from International (Regional) Cooperation and Exchange Program (No. 81250110089), the Key Program from Natural Science Foundation of Chongqing City (No. CSTC2012jjB10026), the Specialized Research Fund for the Doctoral Program of Higher Education of China (No. SRFDP 20110182110007) and the Fundamental Research Funds for the Central Universities (Nos. XDJK2011D007, XDJK2012B026).

国家自然科学基金(No. 21172181)、外国青年学者研究基金(No. 81250110089)、重庆市自然科学基金重点(No. CSTC2012jjB10026)、高等学校博士学 科点专项科研基金(No. SRFDP 20110182110007)、中央高校基本科研业务费专项资金(Nos. XDJK2011D007, XDJK2012B026)资助项目.
} 
生长调节方面取得许多重要的研究成果, 如除草剂四唑 嘧磺隆 (5, Azimsulfuron) 等具有宽广的应用, 有力地促 进农药的绿色化发展; 在材料领域, 四唑类化合物含氮 量高且具较高的正生成焓, 是良好的高密度能量材料, 广泛用于起爆药、固体推进剂等含能材料的制备, 同时 在然料电池、抗金属腐蚀和光敏材料方面的研究也较为 活跃, 四唑类化合物还可作为催化剂用于催化多种反 应，如 Heck，Suzuki 等偶联反应，尤其在不对称合成中 具有较高的催化效率和立体选择性.

四唑类化合物的独特结构性能及与酶、受体以及金 属等的多种作用形式使之表现出特殊的化学、物理和生 物学特性, 引起国内外相关科技工作者的广泛关注, 在 医药、农药、材料等领域的用途不断朝着新的研究方向 拓展. 因此, 有关四唑类化合物的合成受到广泛地重视, 开发了许多成熟的合成法, 取得突破性成果. 鉴于此, 本文基于作者研究组多年唑类研究工作 ${ }^{[1 \sim 3,5 \sim 20]}$, 参考 国内外近五年文献系统地综述了四唑类化合物的合成 及其在医药、农药、材料等领域的应用研究近况.
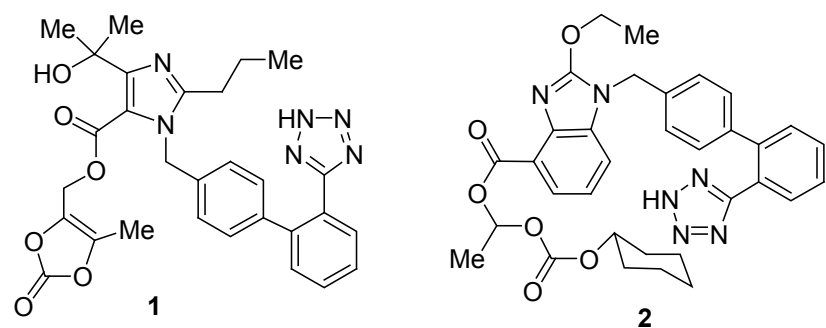<smiles>NCc1ccccc1CC(=O)N[C@H]1C(=O)N2C(C(=O)O)=C(CSc3nnnn3CC(=O)O)CS[C@H]12</smiles><smiles>COc1cc(OC)nc(NC(=O)NS(=O)(=O)c2[nH]ncc2-c2nnn(C)n2)n1</smiles>

3<smiles>CCN1CCN(CNC(C(=O)N[C@H]2C(=O)N3C(C(=O)O)=C(CSc4nnnn4C)CS[C@H]23)c2ccc(O)cc2)C(=O)C1=O</smiles>

\section{1 四唑类化合物的合成}

四唑类化合物宽广的应用前景促使众多工作致力 于其合成研究, 已开发许多成熟的合成方法, 迄今为止 所报道的合成方法主要是以叠氮化物为原料, 包括叠氮 化物与腈、伯胺以及酰胺等类化合物的环化反应. 开发 高效快速、安全稳定、绿色环保的新制备方法仍是近些 年四唑化合物合成方法的热点课题.

\section{1 叠氮化物与腈类化合物环化}

叠氮化物与腈类化合物的环化反应是开发较早且 较为成熟的经典合成方法，广泛用于四唑化合物的制 备. 根据使用的催化剂类型，该类反应可分为非金属催 化环化和金属催化环化.

\subsection{1 非金属催化环化}

一些酸性化合物如氯化铵、三乙胺盐酸盐和醋酸是 叠氮化物与有机腈发生环加成反应的常用的有效催化 剂, 在四唑类化合物的构筑中发挥着重要作用, 已得到 广泛采用. 一般认为, 酸性物质催化腈和叠氮化物环化 合成 5-位取代四唑化合物是 $[2+3]$ 偶极环加成反应机理 (Scheme 1).

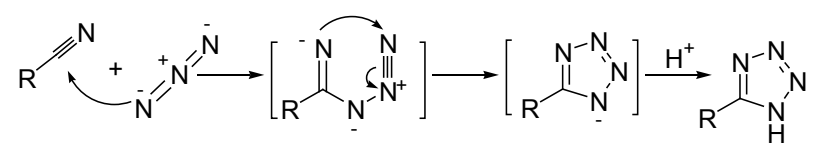

\section{Scheme 1}

氯化铵是常用于催化叠氮化物和有机腈环化合成 四唑化合物常用的无机盐催化剂, 该环化法是制备四唑 化合物经典的合成法，操作简便、成本低、反应时间短、 产率高. 如苯并三唑类丙基腈与 $\mathrm{NaN}_{3}$ 在二甲基甲酰胺 中用 $\mathrm{NH}_{4} \mathrm{Cl}$ 催化可在 $125{ }^{\circ} \mathrm{C}$ 高效环化得到四唑化合物 6, 产率在 $80 \%$ 以上(Eq. 1) ${ }^{[21]}$. 化合物 6 是一种重要的中 间体，可用于合成四唑类抗菌、抗真菌和抗惊厥衍生物.<smiles>N#CCCn1nnc2ccccc21</smiles><smiles>N#[W]</smiles><smiles>c1ccc2c(c1)nnn2CCc1nn[nH]n1</smiles>

用三乙胺盐酸盐代替氯化铵进行催化，四唑化合物 同样可高产率获得，且产物分离也易于进行，目标化合 物可直接从反应混合物的水溶液或碱性溶液中萃取得 到. 联苯腈和 $\mathrm{NaN}_{3}$ 在三乙胺盐酸盐催化作用下, 在甲 苯中回流，以 $87 \%$ 的产率得到四唑化合物 7 (Eq. 2) ${ }^{[22]}$. 该化合物是合成抗高血压药物四唑沙坦类的中间体，该 类合成方法广泛应用此类药物的合成.
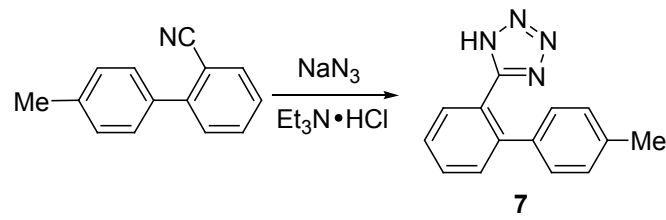

乙酸也是制备四唑化合物的有效催化剂, 若用 $N$ 甲基吡咯烷酩(NMP)作溶剂，可提高反应温度，缩短反 应时间. 乙酸催化下, 二苯基乙腈与 $\mathrm{NaN}_{3}$ 的环化经微 
波辐射 $10 \mathrm{~min}$, 可得到化合物 8 具有 $85 \%$ 的产率(Eq. $3)^{[23]}$. 与传统加热方法相比, 微波合成法具有反应时间 短、效率高等优点.
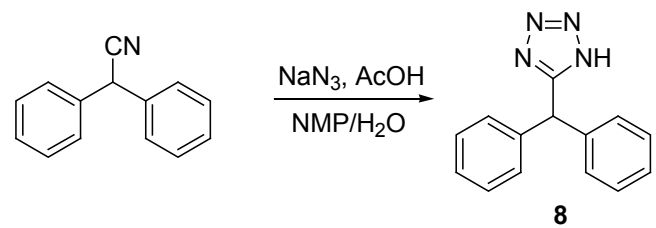

此外, 异腈、异硫腈与叠氮化物也可经 $[2+3]$ 偶极 环加成的反应机理来制备四唑化合物. 其中, 异腈与叠 氮化物的环化是直接在四唑环 1-位引入取代基团的重 要方法 ${ }^{[24,25]}$; 而以异硫腈为原料则是直接制备 5-颈基或 烷烃硫基取代四唑化合物的重要途径 ${ }^{[26]}$

\section{1 .2 金属催化环化}

金属类催化剂因催化效果良好而在有机合成中发 挥着重要作用, 其中有关金属催化合成四唑化合物的相 关工作较多, 研究较为活跃. 其机理与非金属催化环化 类似，不同之处在于金属催化剂不仅能与叠氮酸根络 合, 也能与腈基 $\mathrm{N}$ 配位, 活化腈类化合物, 使其更容易 被 $\mathrm{N}_{3}^{-}$进攻(Scheme 2).

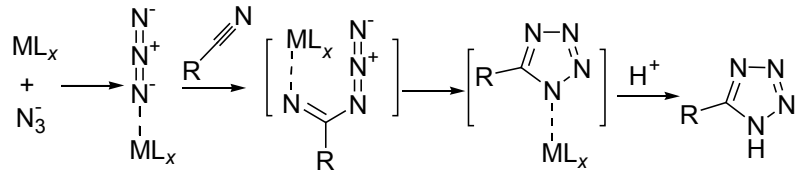

\section{Scheme 2}

铜盐作为催化剂已广泛应用于有机合成领域, 尤其 是一价铜离子 $\left(\mathrm{Cu}^{+}\right)$在 “点击反应” 催化 1,2,3-三唑杂环 化合物的合成中发挥了重要作用 ${ }^{[27]}$. 研究发现铜盐在 环化制备四唑化合物也具有较好的催化效果. 对甲氧基 苯乙腈与叠氮三甲基硅烷在 $\mathrm{Cu}_{2} \mathrm{O}$ 催化作用下回流反应 以 $84 \%$ 的产率得到化合物 9a (Scheme 3) ${ }^{[28]}$. 此类催化方 法操作简便、条件温和、易于实施. 铜-锌合金纳米粒也 能催化该反应合成四唑 $9 \mathrm{a}$, 产率高达 90\%; 当苯环上为 硝基取代时, 其目标产物对硝基苯基四唑 9b 的产率可 达到 96\% ${ }^{[29]}$. 含有叠氮基和腈基的化合物 10 在金属铜 的催化下可发生分子内环化, 以 $81 \%$ 的产率得到稠合哌 嗪四唑 11 (Eq. 4) ${ }^{[30]}$. 该分子内环化法为哌嗪稠环的四 唑类化合物提供了一条有效的制备途径.

金属锌盐作为催化剂在化学与化工生产中也占有 重要地位, 特别是其卤化物在构筑四唑环的催化合成中 得到广泛应用. 取代磺酰亚胺腈和叠氮化钠在 $\mathrm{ZnBr}_{2}$ 催 化作用下，于 $120{ }^{\circ} \mathrm{C}$ 温度下以 $87 \%$ 的高产率得到 5-取代 四唑 12 (Eq. 5) ${ }^{[31]}$. 若使用催化剂 $\mathrm{NH}_{4} \mathrm{Cl}$ 或 $\mathrm{Et}_{3} \mathrm{~N} \cdot \mathrm{HCl}$, 加

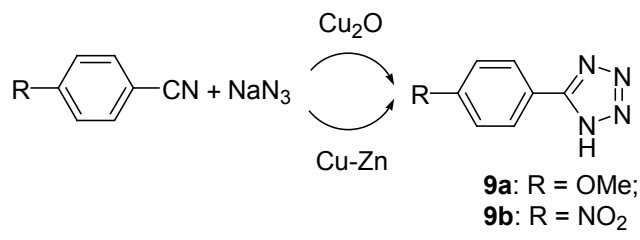

Scheme 3

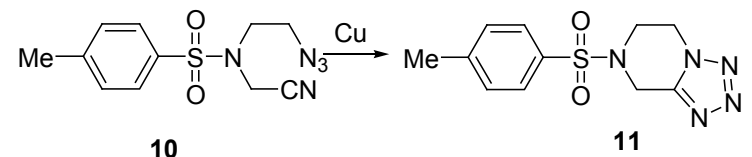<smiles>[Z10][R16]([H])([H])c1cccc(S(C)(=O)=Nc2nnn[nH]2)c1</smiles>

热到 $120{ }^{\circ} \mathrm{C}$ 时 $\mathrm{N}-\mathrm{CN}$ 键会断裂分解，难以得到目标产 物.

金属铁盐在制备四唑环的反应中也具有较好的催 化效果. 芸腈在 $\mathrm{FeCl}_{3}-\mathrm{SiO}_{2}$ 催化作用下与 $\mathrm{NaN}_{3}$ 反应成 功得到芳基四唑化合物 13 (Eq. 6) ${ }^{[32]}$. 该反应在二甲基 甲酰胺或二甲亚砜等有机溶剂中产率 $80 \%$ 以上，若用水 作溶剂，其产率仅为 $6 \%$. 表明溶剂对该反应有较大影 响. 若用磁性 $\gamma-\mathrm{Fe}_{2} \mathrm{O}_{3}$ 纳米粒催化该环化反应, 其目标化 合物产率高达 $80 \%{ }^{[33]}$. 此外, 该制备法方便、高效, 并 且催化剂易分离回收, 可循环利用。

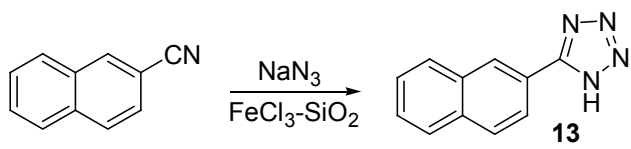

锆的化合物也可用于四唑环的合成，且具有较好的 催化效果. 呋喃腈与 $\mathrm{NaN}_{3}$ 在 $\mathrm{ZrOCl}_{2}$ 催化下于 $100{ }^{\circ} \mathrm{C}$ 发 生环化, 以 $95 \%$ 的高产率得到化合物 14a (Scheme 4) ${ }^{[34]}$. 若用噻吩与 $\mathrm{NaN}_{3}$ 在 $\mathrm{ZrO}_{2}$ 催化下于水溶液中也可顺利发 生 $[2+3]$ 环加成反应生成噻吩四唑 $\mathbf{1 4 b}$, 产率为 $88 \%$; 而选择 DMF 作为溶剂时产率高达 $96 \%{ }^{[35]}$.

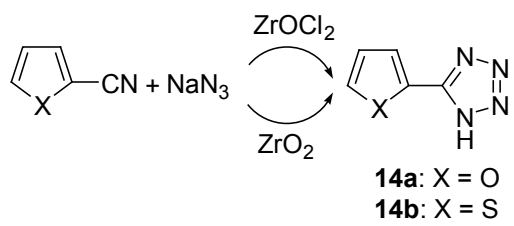

Scheme 4

近些年来, 金属钯因其优异的催化活性和选择性而 广泛应用于有机合成和化工领域，其中在构筑四唑环的 反应中表现出独特的催化性能. 叠氮钯化合物与丙腈在 $125{ }^{\circ} \mathrm{C}$ 微波条件下反应得到四配位的四唑钯络合物 $\mathbf{1 5}$, 该络合物进一步断裂丙腈 $\mathrm{C}-\mathrm{CN}$ 键形成中间体六配位 
钯络合物, 然后失去乙烯分子得到化合物 16a, 同时游 离出 5-乙基四唑 16b (Scheme 5) ${ }^{[36]}$.

一些非过渡金属化合物也可催化腈类化合物和叠 氮化物的环化反应. 在 $\mathrm{Al}\left(\mathrm{HSO}_{4}\right)_{3}$ 催化作用下, 芳氨基 腈与 $\mathrm{NaN}_{3}$ 反应后用水处理得到化合物 $17 \mathbf{a}$ 和异构体 17b, 转化率在 $72 \% \sim 90 \%$ 之间(Scheme 6) ${ }^{[37]}$, 苯环 2-或 4-位有给电子基团时产物以 5-取代四唑为主. 该方法操 作简单, 无需任何溶剂. 天然的钠沸石也可催化该类反 应的发生，产率在 $80 \%$ 以上 ${ }^{[38]}$.

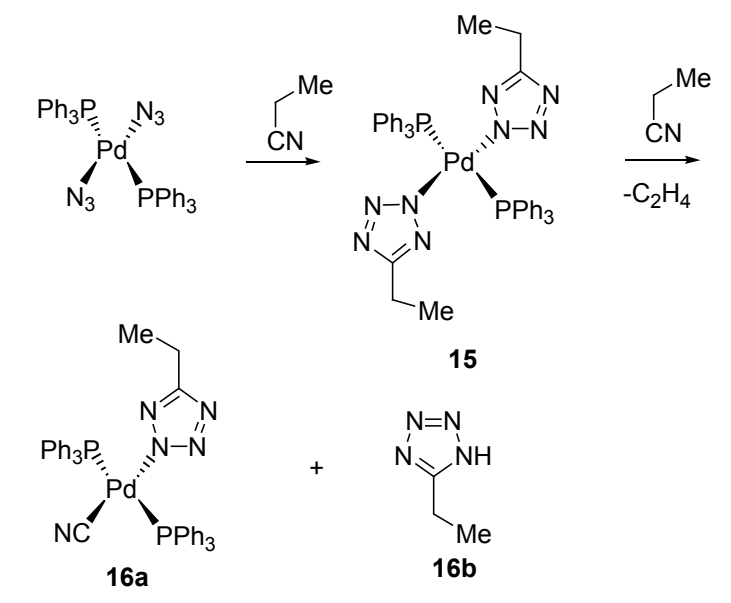

Scheme 5<smiles>N#CNc1ccccc1[W]#N</smiles><smiles>O=S1(=O)CCCCCC1</smiles><smiles>[R]c1cccc(N=C(N)N)c1NC(=N)NCc1ccccc1</smiles>

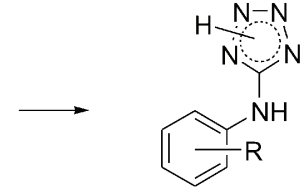

$17 a$

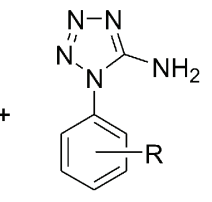

$17 b$
Scheme 6

有机锡如 $\mathrm{Bu}_{2} \mathrm{SnO},(n-\mathrm{Bu})_{3} \mathrm{SnCl}$ 也对四唑化合物的 合成具有较好的催化效果, 特别是其有机锡叠氮 $(n-\mathrm{Bu})_{3} \mathrm{SnN}_{3}$ 具有更加独特的优势. 联苯腈类化合物与 $(n-\mathrm{Bu})_{3} \mathrm{SnN}_{3}$ 发生环化反应, 用盐酸甲醇溶液处理后以 93\%的高产率得到四唑化合物 $\mathbf{1 8}$, 该化合物是抗高血压 药物傾沙坦的重要中间体(Eq. 7 ${ }^{[39]}$. 采用此方法制备缬
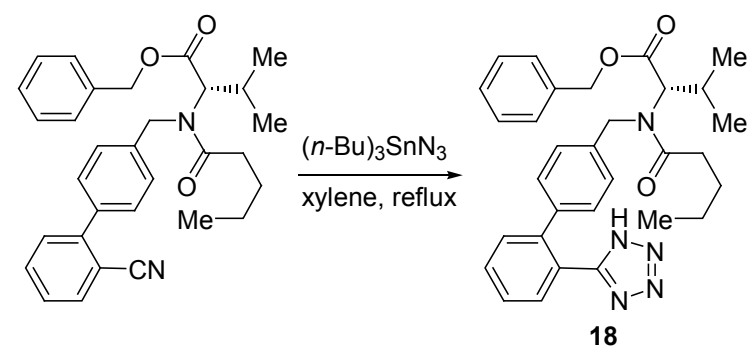

沙坦可有效避免直接使用催化剂 $(n-\mathrm{Bu})_{3} \mathrm{SnCl}$ 带来的产 品分离困难等问题，并且催化剂可循环回收利用.

金属铟的卤化物作为无机均相催化剂具有对水和 空气稳定、催化效率高以及适用范围广等优点，近年来 在有机合成领域颇受关注. 在二甲基甲酰胺中，于 140 ${ }^{\circ} \mathrm{C}$ 下三氯化铟催化对苯二腈与 $\mathrm{NaN}_{3}$ 的环化几乎定量地 制得双四唑化合物 19 (Eq. 8) ${ }^{[40]}$.

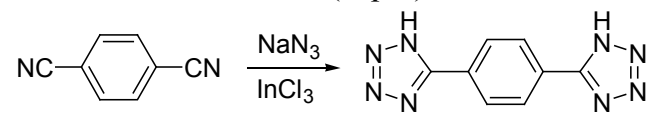

\section{2 叠氮化物与胺类化合物环化}

$1999 \%$

胺类化合物是有机合成化学中应用较为广泛的重 要原料，具有来源较广、容易制备等优点，以胺为原料 构筑四唑环是制备 $N$-四唑类化合物的重要方法之一.

氨基噻吩与叠氮化钠、原甲酸乙酯在乙酸作用下环 化生成化合物 20, 产率高达 $91 \%$ (Eq. 9) ${ }^{[41]}$. 该化合物是 嘧啶类医药分子的重要中间体，其简便高效的合成法为 该类新型杂环药物的深入开发带来了很大的希望.<smiles>CCOC(=O)c1c(N)sc2c1CCC(C)C2</smiles>

芳胺类化合物和叠氮化钠、原甲酸乙酯也可在离子 液体 $\left([\mathrm{bbim}]^{+} \mathrm{Br}^{-}\right)$和二甲亚砜混合溶剂中反应可高产率 得到苯基四唑类化合物 21, 产率在 $80 \%$ 以上(Eq. 10) ${ }^{[42]}$. 该方法高效快速、环保安全，且室温下即可发生. 此外, 该反应在钠沸石催化作用 $4 \mathrm{~h}$ 后也可以 $80 \%$ 的产率得到 目标产物 ${ }^{[43]}$.

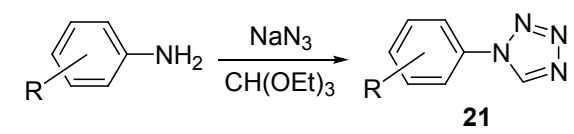

研究表明，原甲酸乙酯参与制备四唑化合物的反应 均具有如下的类似反应机理(Scheme 7).

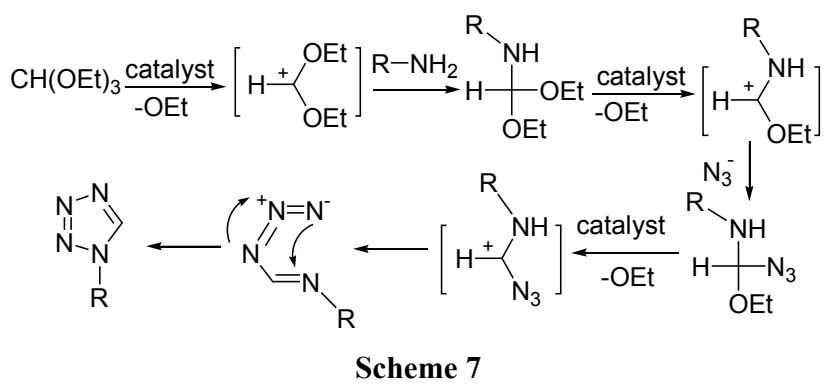

二氟叠氮化物具有良好的安全稳定性, 可与伯胺 在室温下反应来制备含氟的 1,5-二取代四唑类化合物 
$22(\text { Scheme 8) })^{[44]}$. 反应溶剂为 $\mathrm{DMF}$ 时产率为 $60 \%$, 改为 乙醇时产率可提高到 $70 \%$, 并且反应时间大大缩短. 氟 原子的引进可显著改变化合物的生物活性, 该反应为开 发新型高效活性化合物提供了新的可能.

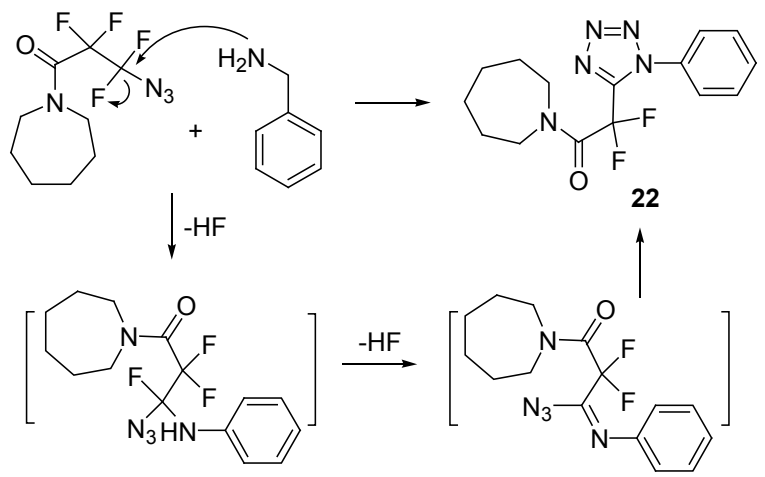

Scheme 8

\section{3 叠氮化物与酰胺类化合物环化}

酰胺类化合物是一类重要的工业原料, 在合成含 氮杂环化合物反应中占有重要的地位. 酰胺和叠氮化物 的反应是制备取代四唑类化合物的又一重要方法，其反 应机理也涉及产生活性亚胺中间体, 然后在 $\mathrm{N}_{3}^{-}$进攻后 发生环加成反应得到 1,5-二取代四唑类化合物.

取代酰胺类化合物 23 在氮气保护下与 $\mathrm{PCl}_{5}$ 反应生 成活性中间体氯代亚胺, 然后在叠氮化物的进攻下发生 环加成反应得到四唑化合物 24. 若此条件下羰基与氨 基互换位置, 则需反应 $48 \mathrm{~h}$ 才得到相应产物(Scheme $9)^{[45]}$. 化合物 24 具有抑制 $11 \beta$-差基类固醇脱氢酶的生 物活性, 对代谢疾病和中枢神经系统紊乱症的治疗表现 出较大潜力.

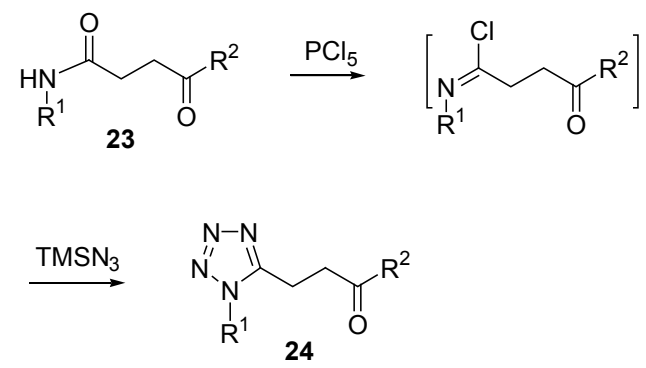

\section{Scheme 9}

$\alpha$-氨基酰胺类化合物 25 在偶氮二甲酸二乙酯、 $\mathrm{Ph}_{3} \mathrm{P}$ 作用下与 $\mathrm{TMSN}_{3}$ 反应 $48 \mathrm{~h}$ 以 $55 \%$ 产率得到化合物 $\mathbf{2 6}$, 该化合物是合成具有促生长素分泌作用活性化合物的 有效中间体(Eq. 11) ${ }^{[46]}$. 虽然该方法经历时间较长, 但 可在室温下进行, 是合成一些良好生物活性分子的重要 反应.

\section{4 其他方法制备四唑化合物}

过渡金属催化作用下选择性断裂 $\mathrm{C}-\mathrm{H}$ 和 $\mathrm{C}-\mathrm{C}$ 键

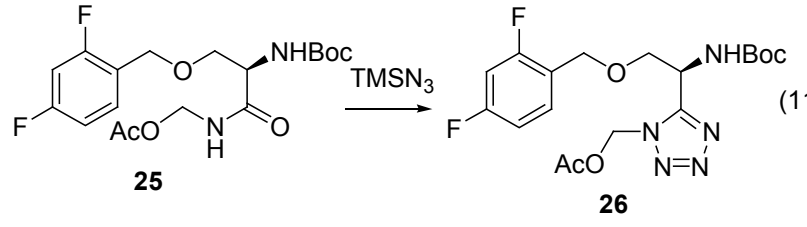

从而实现烷烃分子的直接转化反应在有机合成中具有 广泛的应用潜力. 以对称的芳基烯烃和叠氮三甲基硅烷 为原料, 在氧化剂二氯二氰基苯醌(DDQ)和催化剂 $\mathrm{CuI}$ 作用下可环化得到新奇的四唑化合物 27, 产率可高达 90\% (Eq. 12) ${ }^{[47]}$. 若两个苯环上的取代基以及取代位置 不同时，可生成两种不同的四唑类产物.

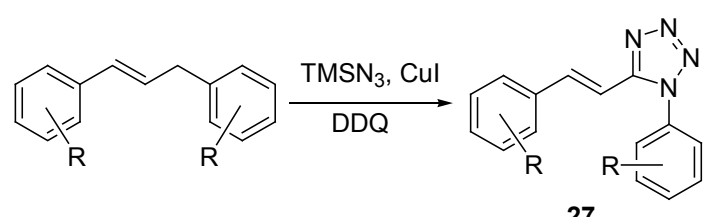

$N$-亚硝基- $N$-环丙基脲在醇钠作用下反应得到互为 异构体的二取代四唑化合物 28a 和 $\mathbf{2 8 b}$, 产率为 55\%左 右(Scheme 10) ${ }^{[48]}$. 该反应有效地保留了原有化合物分 子中的 $\mathrm{N}$ 原子进而引入杂环，在有机合成领域具有很大 的应用潜力.

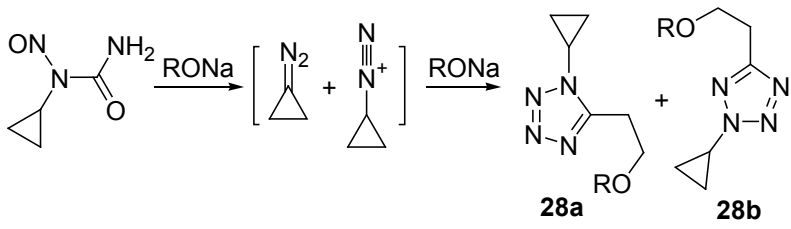

Scheme 10

重氮盐 29 与腙类化合物 30 反应也可制备四唑化合 物 31, 产率可达 81\% (Eq. 13) ${ }^{[49]}$. 该方法需低温控制, 但通过这一反应可有效地实现用四唑环修饰香豆素以 得到特殊生物活性的分子.
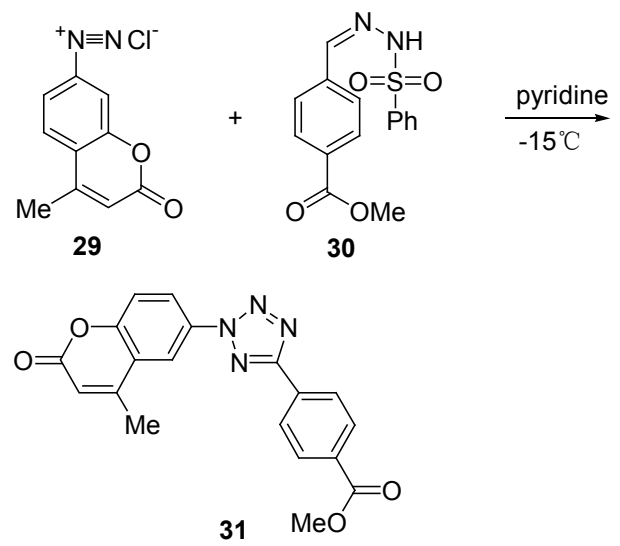

叔丁基异腈与炔、苯磺酰胺发生反应生成中间体 
32, 然后与三甲基叠氮硅烷环化以 $55 \%$ 的总收率得到 1,5-二取代四唑化合物 33 (Scheme 11) ) $^{[50]}$. 该反应操作 简单、条件温和、且不需要催化剂, 是合成含有多功能 基团四唑化合物的有效方法.
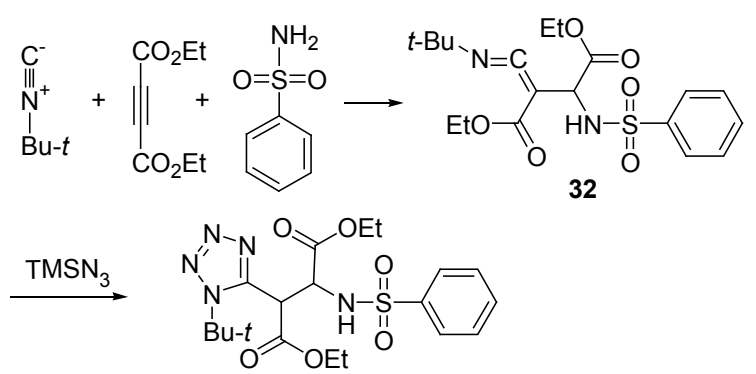

33

\section{Scheme 11}

此外, 利用四唑结构中 $\mathrm{NH}$ 的强亲核性对四唑环进 行结够修饰也是制备四唑衍生物的重要方法, 该类方法 简单有效、易于发生，不再赘述.

\section{2 医药领域的应用研究}

四唑类化合物作为药物可以通过多种非共价键相 互作用与生物体内多种酶和受体等作用靶点结合, 表现 出多种生物活性. 目前已在抗高血压、抗病毒、抗菌、 镇痛消炎、抗癌、抗癫㾁、促生长素分泌、抗氧化、抗 动脉粥样硬化、抗糖尿病等领域得到了广泛研究, 显示 出具有宽广的应用前景和巨大的开发价值.

\section{1 抗高血压类四唑化合物}

高血压是一种常见的频发性疾病，与冠心病和糖尿 病等关系密切, 已对全球公共健康带来严重挑战. 目前 临床上使用的降压效果好、副作用较少的抗高血. 压药物 为血管紧张素 AII (Angiotensin, AII)受体拮抗剂, 其结 构类型多样, 其中以四唑类化合物为代表的沙坦类 (Sartans)药物受到较大关注和广泛研究, 已成为治疗高 血压的主流品种之一.

氯沙坦 $(34$, Lorsartan)是第一个上市的非肽类血管 紧张素 II 受体拮抗剂型抗高血压药, 半抑制浓度 $\mathrm{IC}_{50}$ 值 为 $19 \mu \mathrm{mol} / \mathrm{L}$, 克服了一些临床肽类 $\mathrm{AII}$ 受体拮抗剂的缺 点 ${ }^{[51]}$. 近年来, 大量工作致力于对沙坦类药物结构上咪 唑环的修饰, 得到一系列药效更强、药代动力学性质更 好的降血压药物, 如奥美沙坦酯(1)、坎地沙坦酯(2)、厄 贝沙坦(35, Irbesartan)、缬沙坦(36, Valsartan)、他索沙坦 (37, Tasosartan)的成功上市, 为人类健康带来巨大的福 祉. 尤其是作为前药的奥美沙坦酯和坎地沙坦酯, 在经 肠道时快速地水解为奥美沙坦 (38, Olmesartan)和坎地沙 坦(39, Candesartan), 二者对 AII 受体具有高效的拮抗作

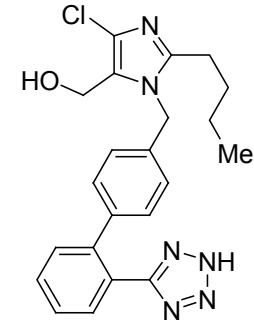

34

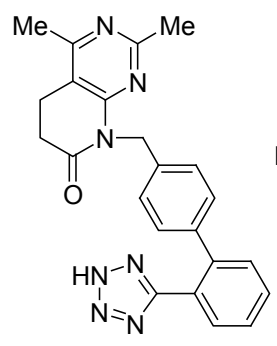

37

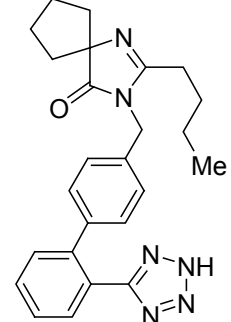

35

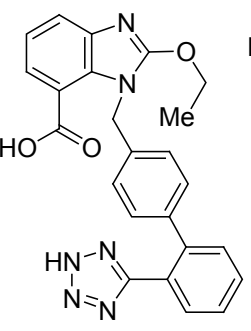

38

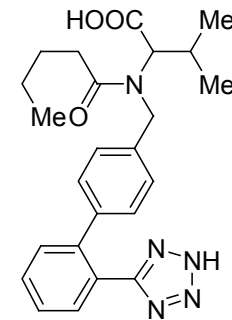

36

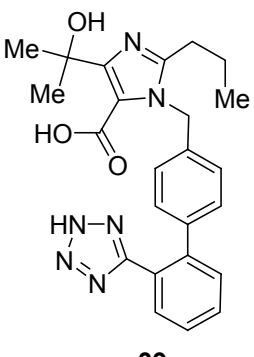

39
用，迅速地起到降压作用.

超分子药物具有许多优点，在调节药物理化性质、 改善生物活性及利用度方面发挥着重要作用, 其研发已 成为异常活跃的研究领域 ${ }^{[52 \sim 55]}$, 厄贝沙坦(35)具有较高 的脂溶性, 与血管紧张素 II 受体结合的亲和力为氯沙坦 的 10 倍, 但其水溶性很差 $(67.8 \mu \mathrm{g} / \mathrm{mL})$, 这可能是导致 其在临床上的疗效不佳的重要因素 ${ }^{[56]}$. 与 $\beta$-环糊精形成 包结络合物后, 其水溶性可显著增加, 溶解度可达到 $137.6 \mu \mathrm{g} / \mathrm{mL}$, 尤其是在二者混合物中加入 PVP K-90 或 PEG 4000 后形成的新混合包结络合物的水溶性可分别 达到 331.19 和 $345.63 \mu \mathrm{g} / \mathrm{mL}^{[57]}$. 因此, 厄贝沙坦通过与 $\beta$-环糊精形成包结超分子络合物以其提高水溶性, 这为 其药理活性的发挥提供了新方法.

引入三唑酮片段的四唑类化合物 $\mathbf{4 0}$ 对 AII 受体具 有很强的结合作用，与现有的四唑沙坦类抗高血压药物 不同, 其结构中不含有药效基团联苯基四唑. 在血压升 高的小鼠试验中, 静脉注射 $3 \mathrm{mg} / \mathrm{kg}$ 的化合物 $\mathbf{4 0}, 30 \mathrm{~min}$ 后便可达到最大降压量 $(22 \mathrm{mmHg}, 2.92 \mathrm{kPa})$, 且抗高血 压作用可持续 $150 \mathrm{~min}$ 以上, 而参比药物氯沙坦在 10 $\mathrm{mg} / \mathrm{kg}$ 剂量下需经 $90 \mathrm{~min}$ 才达到最大降压量 $(18 \mathrm{mmHg}$, $2.39 \mathrm{kPa})$, 显示出具有很大的开发潜力 ${ }^{[58]}$.

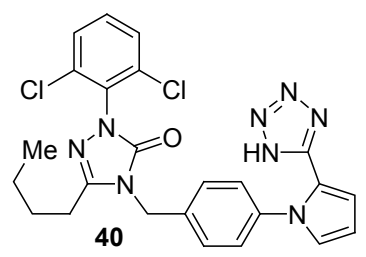

盐皮质激素受体的异常激活是导致高血压和心脏 衰竭等其他心血管系统疾病的重要因素之一. 含嘧啶基 
团的四唑类化合物 41 与盐皮质激素受体具有很强的结 合作用 $\left(\mathrm{IC}_{50}=64 \mathrm{nmol} / \mathrm{L}\right)$, 可阻断受激靶基因的转录来 达到降低血压的效果. 此外, 该化合物具有较好的水溶 性, 稳定的代谢途径且对细胞色素没有抑制倾向, 有望 进入临床研究 ${ }^{[59]}$.

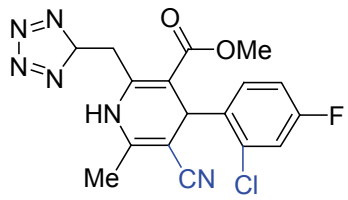

41

\section{2 抗病毒类四唑化合物}

病毒性感染是严重威胁人类健康的传染性疾病之 一. 病毒增殖速度快、易产生突变、抗药耐药性不断增 强以及新病毒的出现迫切需要研发出结构新型、作用机 制不同的抗病毒药物. 近年来, 以四唑环为基体构建的 抗病毒活性分子在抗病毒领域表现出较大潜力, 已成为 抗病毒药物研发的重要研究方向.

\subsection{1 抗 HIV 类四唑化合物}

非核苷类逆转录酶抑制剂(NNRTIs)是一类独特的 抗病毒药物, 具有高效、低毒、专一性等优点. 芳基硫 代四唑类衍生物 42 是一种高效的 HIV-1 非核苷类逆转 录酶抑制剂，其结构简单新颖，与其他已报道的 HIV-1 非核苷类逆转录酶抑制剂的化学结构明显不同. 该化合 物对 HIV 原生型(WT)和突变株 K103N/Y181C 的半抑制 浓度 $\mathrm{IC}_{50}$ 值分别为 9.5 和 $766 \mathrm{nmol} / \mathrm{L}^{[60,61]}$. 对其结构进 行修饰, 将四唑环 1-位的荟环用 2-氯苯基替换得到的化 合物 43 对 $\mathrm{WT}$ 和 $\mathrm{K} 103 \mathrm{~N} / \mathrm{Y} 181 \mathrm{C}$ 的抑制能力降低, $\mathrm{IC}_{50}$ 值分别为 39 和 $1995 \mathrm{nmol} / \mathrm{L}$; 当该苯环的 4-位有叔丁基 取代以及另一苯环上 2-位为氯取代时, 对 WT 和 K103$\mathrm{N} / \mathrm{Y} 181 \mathrm{C}$ 的 $\mathrm{IC}_{50}$ 值可分别达到 3 和 $27 \mathrm{nmol} / \mathrm{L}^{[62]}$, 生物 活性明显增强.
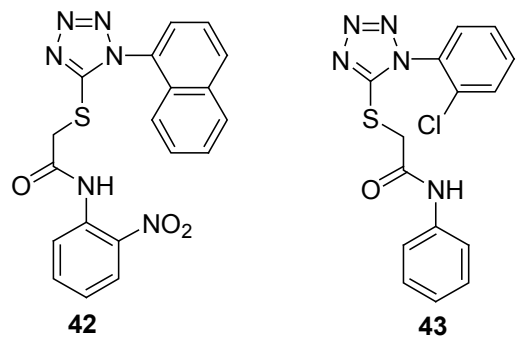

此外, 将化合物 42 分子结构中的 $\mathrm{CONH}$ 替换成 $\mathrm{CONHN}=\mathrm{C}$ 得到化合物 44 , 该化合物可选择地抑制 HIV-1 的复制过程, 而对 HIV-2 复制过程没有影响. 构 效关系研究结果显示, 链长的增加改变了分子的柔性从 而导致分子与 HIV 病毒受体结合时的适应性发生改变, 进而选择性地抑制 HIV-1 复制, 其半数有效浓度 $\mathrm{EC}_{50}$
值达到 $29.62 \mu \mathrm{mol} / \mathrm{L}$. 因此对该类化合物的进一步研究 具有重大的意义，为新型抗 HIV 药物的设计开发提供了 基础 ${ }^{[63]}$.

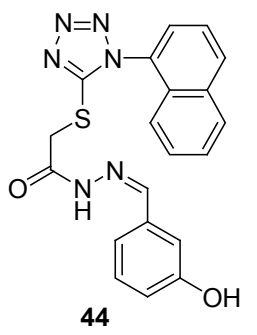

含有多个酚差基的四唑类衍生物 45 是抗病毒药物 二咖啡因酒石酸(L-CA)的一种类似物，对 HIV 整合酶具 有较强的抑制能力. 体外活性和构效关系研究表明，分 子结构中含有两个四唑环的化合物 $\mathbf{4 5 b}$ 的抗 HIV 活性 优于单四唑化合物 45a; 苯环上有三个羟基取代时, $\mathrm{EC}_{50}$ 值低至 $0.06 \mu \mathrm{mol} / \mathrm{L}$, 抗病毒能力是参考药物 L-CA 的近 30 倍. 此外，该类化合物的抗 HIV 治疗指数(TI)均 高于 $350^{[64]}$, 有望成为抗 HIV 的临床候选药物.

核苷类抗 HIV 逆转录酶抑制剂的结构中引入 1,3二氧络和 4-氟茮基，不仅可以提高化合物的生物活性， 还能减少毒性代谢物的产生. 研究表明，化合物 46 对 $\mathrm{HIV}$ 整合酶显示出较好的抑制作用, $\mathrm{EC}_{50}$ 值为 0.24 $\mu \mathrm{mol} / \mathrm{L}$, 细胞毒性值为 $130 \mu \mathrm{mol} / \mathrm{L}$, 可作为先导分子进 行深入研究 ${ }^{[65]}$.

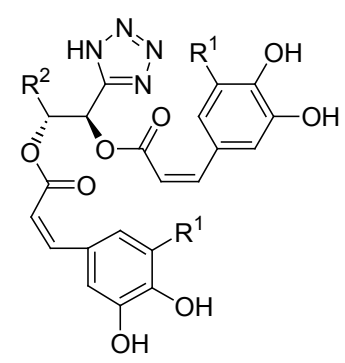

45a $\mathrm{R}^{1}=\mathrm{H}, \mathrm{R}^{2}=\mathrm{CONH}_{2}$;

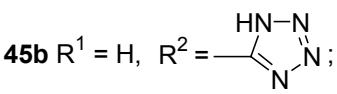

$45 \mathrm{c} \mathrm{R}^{1}=\mathrm{OH}, \mathrm{R}^{2}=\mathrm{N}_{\mathrm{N}^{-}}^{\mathrm{HN}-\mathrm{N}}$

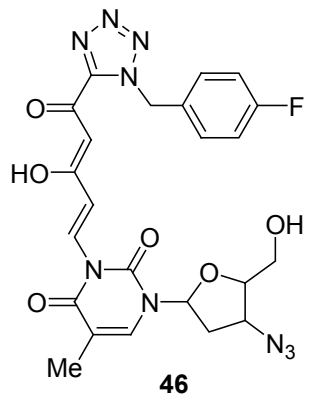

46

\subsection{2 抗丙型肝炎病毒类四唑化合物}

目前临床上治疗丙型肝炎病毒药物存在响应率低 和副作用严重等缺点, 大量文献表明四唑类化合物可作 为一些酶或受体抑制剂以有效地阻断丙型肝炎病毒复 制, 有望在不远的将来克服现有临床药物的不足, 为新 型高效抗丙型肝炎病毒药物的研发提供新的方向.

含有噻唑环的四唑类化合物 47 具有较好的抗丙型 肝炎病毒活性, 对 NS5B 聚合酶显示出较强的抑制能力, $\mathrm{IC}_{50}$ 值达到 $9.7 \mu \mathrm{mol} / \mathrm{L}$. 体外活性研究显示，与 NS5B 聚 
合酶的结合能力强于其羧酸类似物, 有望成为新型的 HCV 病毒 NS5B 抑制剂[66].

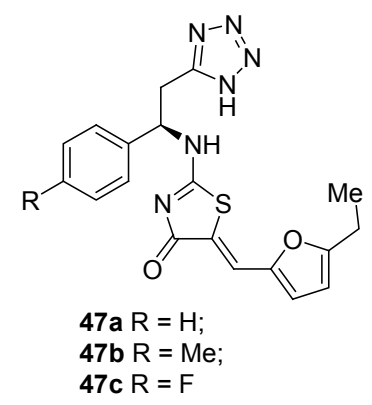

以 NS3 蛋白酶为作用靶点的具有喹啉环骨架结构 的四唑类化合物 48 表现出较好的抗丙型肝炎病毒活性, $\mathrm{EC}_{50}$ 值为 $2.8 \mu \mathrm{mol} / \mathrm{L}$, 活性弱于相应的羧酸化合物 $\left(\mathrm{EC}_{50}=0.14 \mu \mathrm{mol} / \mathrm{L}\right)$, 但其新颖的结构和对 NS3 蛋白酶 的强结合能力显示出其具有进一步的研发价值 ${ }^{[67]}$.

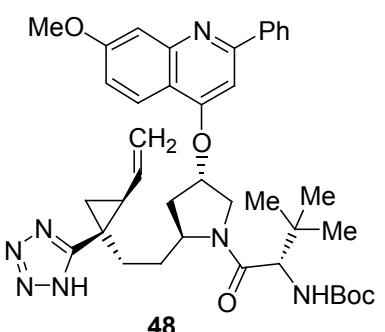

此外, 金刚乙胺(Rimantadine)是常用的抗流感药物, 对 $\mathrm{A}$ 型流感病毒具有较强的抵抗作用, 但是病毒基因的 高突变率易导致耐药菌株的产生, 不利于其临床效果的 较好发挥. 在金刚烷的结构中引入四唑环活性片段对其 结构进行修饰得到的四唑金刚烷类化合物 49 和 $\mathbf{5 0}$, 二 者具有较好抗流感病毒 $\mathrm{H} 1 \mathrm{~N} 1$ 活性, $\mathrm{EC}_{50}$ 值分别为 3 和 2 $\mu \mathrm{g} / \mathrm{mL}$, 均优于参比药物金刚乙胺的抗流感病毒活性 $\left(\mathrm{EC}_{50}=5 \mu \mathrm{g} / \mathrm{mL}\right)$, 显示出巨大的开发潜力 ${ }^{[68]}$.

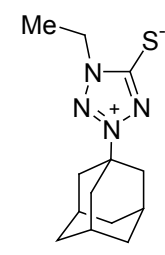

49

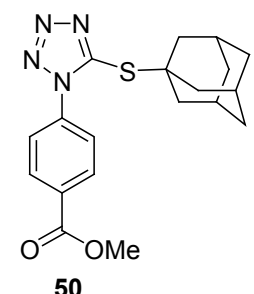

50

\section{3 抗菌类四唑化合物}

细菌感染是诱发高死亡率和发病率的一个重要的 因素, 细菌耐药性的产生以及新型超级病菌的出现对人 类健康造成严重威胁, 因此开发新型高效的抗菌药是全 球性的迫切任务. 四唑类化合物因具有良好的抗菌活性 而受到广泛关注, 目前已应用于临床的四唑类抗菌药如 头孢唑林 $\mathbf{5 1}$, Cefazolin)、头孢尼西(52, Cefonicid)、氟氧
头孢 $(\mathbf{5 3}$, Flomoxef $)$ 以及头孢替坦 $(\mathbf{5 4}$, Cefotetan)等均具 有良好的抗菌效果.<smiles>[H][Y6]1([H])[C@H](NC(=O)Cn2cnnn2)C(=O)N2C(C(=O)O)=C(CSc3nnc([N+](=O)[O-])s3)CS[C@H]21</smiles><smiles>O=C(O)C1=C(CSc2nnnn2CO)CS[C@H](C(=O)NC(=O)C(O)c2ccccc2)N1C(=O)O</smiles>

52<smiles>CO[C@]1(NC(=O)CSC(F)F)C(=O)N2C(C(=O)O)=C(CSc3nnnn3CCO)CO[C@H]21</smiles>

53<smiles>CO[C@]1(NC(=O)C2CC(=C(C(N)=O)C(=O)O)C2)C(=O)N2C(C(=O)O)=C(CSc3nnnn3C)CS[C@@H]21</smiles>

54

头狍唑林 $(\mathbf{5 1})$ 为第一代头孢菌素类抗生素, 对耐青 霉素酶的金黄色葡萄球菌、链球菌、肺炎球菌、白喉杆 菌及梭状芽胞杆菌等有较强的抗菌活性, 对一些革兰阴 性菌的也有较强的抑菌作用, 尤其对克雷白肺炎杆菌的 抑制效果最好. 值得注意的是, 头孢唑林可与 $\mathrm{Cu}$ (II)、磺 胺噻唑(Hstz)反应形成混合络合物 $[\mathrm{Cu}(\mathrm{cefazol})(\mathrm{stz})-$ $\left(\mathrm{H}_{2} \mathrm{O}\right)$ ], 其具体晶体结构形式暂不清楚, 但具有较好的 抑菌作用, 活性与头孢唑林相当 ${ }^{[69]}$.

头孢尼西(52)为第二代广谱长效头孢菌素, 对 $\beta$-内 酰胺酶稳定, 对革兰氏阴性菌的抑制效果较第一代头孢 菌素强, 尤其对线粒体的肉毒碱和酰基肉毒碱的反向运 输具有较强的抑制作用, $\mathrm{IC}_{50}$ 值为 $6.8 \mathrm{mmol} / \mathrm{L}$, 优于头 孢唑林 $\left(\mathrm{IC}_{50}=36 \mathrm{mmol} / \mathrm{L}\right)^{[70]}$.

氟氧头孢(53)被形容为第四代头孢菌素类抗生素, 具有极佳的抗革兰阴性菌活性，同时对包括甲氧西林耐 药金黄色葡萄球菌(MRSA)在内的多种革兰阳性菌也有 抗菌活性. 体外研究表明, $16 \mu \mathrm{g} / \mathrm{mL}$ 或更低浓度的氟氧 头孢能普遍抑制对其敏感细菌, $2 \mu \mathrm{g} / \mathrm{mL}$ 或更低剂量的 氟氧头孢对变形菌属细菌均具有较好抑制作用 ${ }^{[71]}$.

磺胺类抗菌药在预防和治疗人体细菌感染方面曾 发挥重要作用，但耐药性问题使其在临床上的应用受到 限制. 将其结构进行优化得到四唑类化合物 55. 其中化 合物 55a 对小肠结肠炎耶尔森菌具有良好的抑菌作用, 而参比抗生素药物磺胺甲噁唑(Sulfamethoxazole)和磺 
胺甲嘧啶(Sulfamerazine)却对其没有任何抑制效果 ${ }^{[72]}$. 而化合物 55b 则具有较好的抗真菌活性, 主要通过抑制 致病真菌的 $\mathrm{H}^{+}-\mathrm{ATP}$ 酶活性发挥抑菌作用 ${ }^{[73]}$.

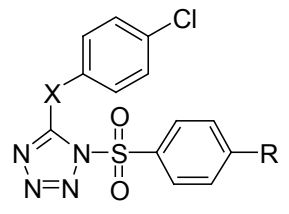

55a $\mathrm{R}=\mathrm{Me}, \mathrm{X}=\mathrm{Se}$;

55b $\mathrm{R}=\mathrm{Cl}, \mathrm{X}=\mathrm{CH}=\mathrm{CH}$

四唑类色酮化合物 56 对 MRSA 具有较好的抗菌活 性, MIC 值在 $0.5 \sim 2.0 \mu \mathrm{g} / \mathrm{mL}$ 范围之间. 其中化合物 56a 对 MRSA 的抗菌活性最好, 与庆大霉素(Gentamycin)相 当 $(\mathrm{MIC}=0.5 \mu \mathrm{g} / \mathrm{mL})$. 除此之外, 化合物 56a 对粪球菌 和肺炎双球菌也有较好的抑菌效果 ${ }^{[74]}$.

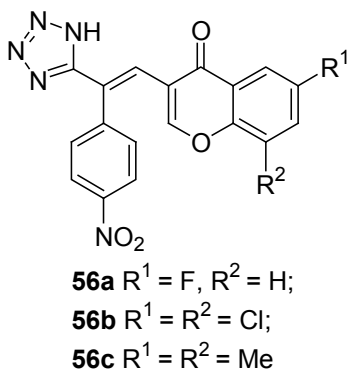

四唑吲哚类衍生物 57 是一种具有新型结构的抗菌 活性化合物, 对革兰阳性菌枯草芽孢杆菌、乳链球菌和 革兰阴性菌大肠杆菌、铜绿假单胞菌具有较强的抑菌能 力, 与参考药物环丙沙星(Ciprofloxacin)相当. 此外, 该 化合物对青霉菌和白色念珠菌也有很高的抑制活性, $\mathrm{MIC}$ 值分别为 0.14 和 $0.1 \mathrm{mg} / \mathrm{mL}$, 与参照药物夫西地酸 (Fusidic Acid)相近 ${ }^{[75]}$.

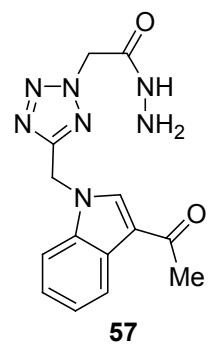

\section{4 镇痛消炎类四唑化合物}

非甾体抗炎药因抗炎效果好、副作用小而受到广泛 关注, 成为抗炎药物研究和开发的重点, 尤其是在炎症 发病机制过程中起重要作用的环氧化酶(COX-2)结构的 确认, 为消炎镇痛类药物的研发提供了更加明确的方 向. 四唑类化合物作为环氧化酶 2 抑制剂具有选择性 高、抗炎镇痛效果好、副作用小的特点, 为新型非甾体
类镇痛消炎药物的研发提供新的思路.

抗炎镇痛药物罗非昔布 (Rofecoxib) 和伐地考昔 (Valdecoxib)对心血管存在不良影响易引发心肌梗死, 导致其使用受到严格限制，为了寻找新的安全高效的消 炎镇痛药物，对其结构进行修饰得到罗非昔布类似物 58 和塞来昔布类似物 59, 二者均具有抗炎活性. 在 3 $\mathrm{mg} / \mathrm{kg}$ 剂量下对大鼠实施静脉注射, 给药 3 和 $5 \mathrm{~h}$ 后, 化 合物 58 分别减少炎症 $34 \%$ 和 $28 \%$, 化合物 59 则分别减 少炎症 40\%和 35\%, 而参考药物帕瑞考昔(Parecoxib)的 炎症减少量分别为 $63 \%$ 和 $42 \%$. 虽然其抗炎效果较参考 药物帕瑞考昔弱，但二者的水溶性较高且对胃粘膜无明 显伤害，具有进一步研发价值 ${ }^{[76]}$.<smiles>O=C1OCC(c2ccc(-c3nn[nH]n3)cc2)=C1c1ccccc1</smiles><smiles>Cc1ccc(-c2cc(C(F)(F)F)nn2-c2ccc(-c3nnn[nH]3)cc2)cc1</smiles>

59

四唑是酰胺的重要生物电子等排体, 利用电子等排 原理合成得到的化合物 60 对 COX-2 显示出较高的选择 性. 抗炎活性研究表明, 化合物 $60 \mathrm{a}$ 和 $60 \mathrm{~b}$ 的 $\mathrm{IC}_{50}$ 值分 别为 2.0 和 $2.7 \mu \mathrm{mol} / \mathrm{L}$, 对 COX-2 的选择性指数值分别 为 210 和 273 , 具有很大的开发潜力 ${ }^{[77]}$.

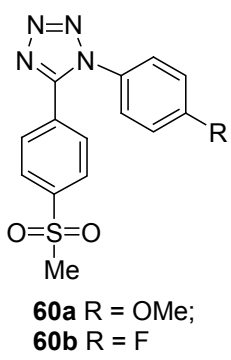

具有 $\alpha$-羊弪基酰胺片段的四唑类化合物 61 可通过对 缓激肽 $\mathrm{B}_{1}$ 的拮抗作用而达到消炎镇痛作用，有效抑制 量低至 $0.41 \mathrm{nmol} / \mathrm{L}$, 同时具有多种转化途径从而降低 了药物与药物之间因相互作用带来的危险，并且没有大 量活性循环代谢产物的产生，因此被选为前临床开发的 备选化合物 ${ }^{[78]}$.

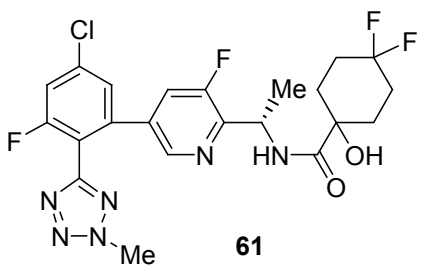

吗啡葡萄糖醛酸苷(M6G)是吗啡的活性代谢产物之 
一, 镇痛效果比吗啡本身强 100 倍, 但是副作用较多且 透过血脑屏障的能力不及吗啡, 用四唑环修饰 M6G 后, 其镇痛作用和持续时间将显著增强. 在小鼠轻打尾研究 结果表明, 给药量为 $1.25 \mathrm{mg} / \mathrm{kg}$ 时, 化合物 $\mathbf{6 2}$ 的镇痛效 果接近 $100 \%$, 远远优于对照药物吗啡和 $\mathrm{M}_{6 \mathrm{G}}{ }^{[79]}$.

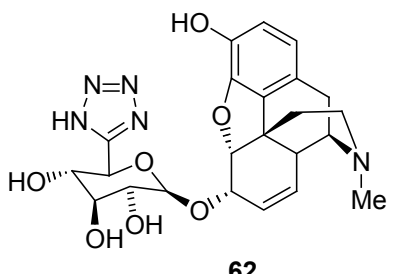

吡啶四唑类化合物 63a 为 P2X7 受体抑制剂, 对机 械性异常疼痛和持续性疼痛具有较好的抑制效果, $\mathrm{ED}_{50}$ 值为 $76 \mu \mathrm{mol} / \mathrm{kg}$. 体内电生理研究进一步表明, 该化合 物可抑制静脉给药后不同类型脊髓神经元的诱发和自 发放电. 构效关系研究显示, 1 -位 $\mathrm{N}$ 上吡啶亚甲基被芐 基取代后的化合物 63b 以及其同分异构体 64 均对 P2X7 受体表现出较强的抑制能力, 但其水溶性较差, 限制了 其成药的可能 ${ }^{[80]}$.

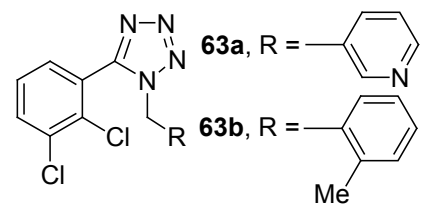<smiles>Clc1cccc(-n2nnnc2Cc2cccnc2)c1Cl</smiles>

\section{5 抗癌类四唑化合物}

目前有关癌症预防和治疗的医疗技术已取得重大 进展, 但是癌症的频发性和多样性以及抗癌药物的高毒 性、低选择性仍然难以满足治疗需求 ${ }^{[11,82]}$. 近些年来, 有关四唑类化合物在抗癌领域的研究工作较为活跃, 呈 现出巨大的研发潜力.

基质金属蛋白酶(MMPs)亚型结构的过度表达是恶 性肿瘤最为显著的特征之一, 特别是 MMP-2 和 MMP-3 与恶性胶质瘤的入侵和血管生成密切相关的临床研究 成果已被深入报道. 化合物 65 为第三代 MMP 抑制剂, 副作用少, 对 MMP-2, MMP-9和 MMP-14 有选择性抑制 作用, 其中对 MMP- 2 和 MMP-9 的完全抑制剂量分别为 10 和 $100 \mu \mathrm{mol} / \mathrm{L}$. 体外和体内研究均表明, MMI-166 对 3 种人类胶质瘤细胞株 T98G, U87MG 和 ONS12 均有较 好的抑制作用 ${ }^{[83]}$. 对其结构进行修饰得到的化合物 66 对 MMP-2 具有良好的选择抑制活性, 其半抑制浓度 $\mathrm{IC}_{50}$ 值为 $32 \mu \mathrm{mol} / \mathrm{L}^{[84]}$.

光动力学疗法是一种冷光化学反应, 其基本要素是 氧、光敏剂和可见光(常用激光). 呋仑碳(Fullerene)是一 种优良的用于光动力学疗法治疗肿瘤和其他感染病症
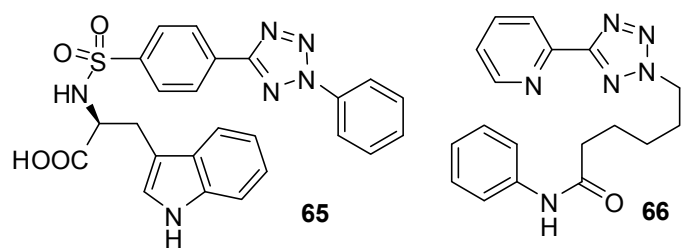

的光敏剂. 利用四唑对其结构进行修饰后，化合物 67a 也具有较好的光化学性质, 可作为光敏剂应用于光动力 学疗法 ${ }^{[85}$. 化合物 67b 结构中四唑环不经过硫而直接与 碳原子相连, 在 $375 \mathrm{~nm}$ 光照下, 它的光敏化效率 (2.39 和 $1.82 \mathrm{ROS} / 10^{6}$ 分子)优于呋仑碳( $1 \mathrm{ROS} / 10^{6}$ 分子), 有 望成为新型的光动力学疗法光敏剂以用于癌症的治 疗 $^{[86]}$.

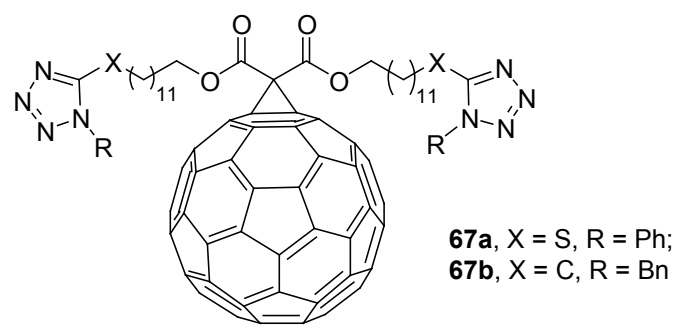

四唑酮类化合物 68 对白血病细胞 L1210 具有抗细 胞增殖活性, $\mathrm{IC}_{50}$ 值为 $2.5 \mu \mathrm{mol} / \mathrm{L}$. 同时该化合物对 SK-BR-3 乳腺癌细胞增殖生长也有抑制作用. 当羰基氧 原子被硫原子替代后得到的四唑硫酮类化合物，抗增殖 活性与前者相似 ${ }^{[87]}$.<smiles>O=c1n(-c2ccccc2)nnn1-c1ccccc1O</smiles>

六亚甲基二乙酰胺(HMBA)具有较好抗白血病细胞 增殖的活性，由非性亚甲基链连接两个强极性基团的特 殊分子构型是其抑制癌细胞增殖的关键. 根据生物电子 等排原理, 将乙酰胺部分用四唑替换得到化合物 69 . 与 HMBA 相比, 该化合物的抗白血病细胞增殖活性具有 时间和浓度依赖性, 并且在诱导白血病细胞分化的同时 能够有效提高血红蛋白含量 ${ }^{[88]}$.

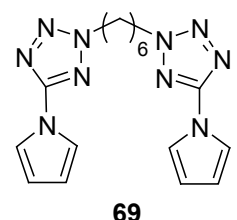

考布他汀 A-4 (Combretastatin A-4)是一种高效的抗 有丝分裂药物, 但是在储存和代谢过程中其顺式构型易 
于向稳定的反式构型转变, 导致其活性明显降低, 因此 无数工作致力于其类似物的设计研究. 用芳基化四唑替 换其烯键得到的化合物 70 在体外抗细胞增殖研究中对 海拉癌细胞株 HeLa 和人乳腺癌细胞系 MCF-7 具有较好 的抑制作用, $\mathrm{IC}_{50}$ 值分别为 1.9 和 $2.3 \mathrm{nmol} / \mathrm{L}$, 抗增殖活 性优于考布他汀 A-4 $\left(\mathrm{IC}_{50}=4\right.$ 和 $\left.370 \mathrm{nmol} / \mathrm{L}\right)$, 有望开发 成抗有丝分裂药物 ${ }^{[89]}$.<smiles>COc1ccc(-c2nnnn2-c2cc(OC)c(OC)c(OC)c2)cc1</smiles>

\section{6 抗癫㾋类四唑类化合物}

癫㾁是脑内异常放电而导致的神经性疾病. 传统的 抗癫㾁药物苯巴比妥(Phenobarbitone)、苯妥英(Phenytoin)具有很强的抗惊厥作用, 但是毒副作用较大, 限制 了它们在临床上的使用. 四唑类化合物作为抗癫㾁试剂 具有脂溶性好、代谢稳定、毒性小和抗癫㾁作用强等优 点, 成为药物化学工作者研究的重点方向之一.

第三代抗癫㾁药物加巴喷丁 (Gabapentin)具有毒性 小、不良反应少、易透过血脑屏障以及与其他抗癫㾁药 物联用时无相加性副作用等特点. 利用生物电子等排原 理, 用四唑替代加巴喷丁分子中的羧基, 得到同样具备 抗惊厥能力的化合物 $\mathbf{7 1}, \mathrm{ED}_{50}$ 值为 $3.1 \mathrm{mg} / \mathrm{kg}$, 且效果优 于加巴喷丁 $\left(\mathrm{ED}_{50}=12.5 \mathrm{mg} / \mathrm{kg}\right)^{[90]}$.

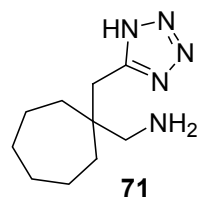

普瑞巴林(Pregabalin)可用于治疗各种形式的癫㾁 症, 其抗癫㾁能力优于加巴喷丁. 对其结构进行修饰得 到的化合物 72 具有更强的抗癫㾁作用. 在 DBA/2 小鼠 抗听原性癫㾁发作试验中, 按 $30 \mathrm{mg} / \mathrm{kg}$ 剂量给药, 两个 小时后，该化合的抗癫㾁保护作用可达到为 $80 \%{ }^{[91]}$.<smiles>CC(C)CC(CN)c1nnn[nH]1</smiles>

喜保宁(Sabril)是一种具有高度选择性的 GABA 氨 基转移酶抑制剂, 可通过提高脑内的 GABA 浓度而产 生抗癫㾁的作用. 用四唑环修饰其结构得到化合物 73 的抗癫㾁能力 $\left(\mathrm{kinact} / \mathrm{KI}=2.48 \mathrm{~min}^{-1} \cdot \mathrm{mmol} \cdot \mathrm{L}^{-1}\right)$ 比喜保
宁更强 $\left(\mathrm{kinact} / \mathrm{KI}=1.7 \mathrm{~min}^{-1} \cdot \mathrm{mmol} \cdot \mathrm{L}^{-1}\right)$, 并且易透过血 脑屏障, 其亲脂性 $(C \log P=-0.48)$ 是喜宝宁 $(C \log P=$ $-2.22)$ 的 55 倍, 具有很大的开发潜力 ${ }^{[92]}$.

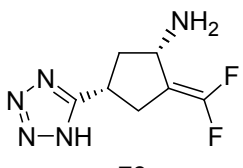

73

\section{7 促生长素分泌类四唑类化合物}

老龄化社会问题的加剧已成为全球关注的焦点之 一. 肌肉功能减退是影响老年人的健康的一大重要因 素, 人生长激素(Human growth hormone)补偿疗法在预 防该类病症的初步研究中取得重要成果. 目前用于临床 的促生长激素分泌药物在超过生理剂量下才能维持全 身血液循环的有效水平，长期使用会产生浮肿、关节痛 和高血糖等多重不良症状. 四唑类促生长激素分泌试剂 具有高效、副作用小的优点，在保障老年人健康方面表 现出巨大潜力.

含有多个酰胺键的四唑类化合物 74 具有较高水溶 性和高效的促生长激素分泌活性, 在小鼠静脉注射模型 中, $\mathrm{ED}_{50}$ 值为 $0.08 \mu \mathrm{mol} / \mathrm{L} / \mathrm{kg}$, 已被选为临床开发候选药 物 ${ }^{[93]}$. 对其构效关系进一步研究，在其氨基甲酸酯处进 行修饰得到的化合物 75 表现出良好的促生长激素分泌 活性. 在 $0.17 \mu \mathrm{mol} / \mathrm{L} / \mathrm{kg}$ 剂量下, 可使体内生长素含量 增加 4 10 倍. 其中，化合物 75c 的活性最高，其最低有 效浓度 $\mathrm{MIC}$ 值可低至 $0.017 \mu \mathrm{mol} / \mathrm{L} / \mathrm{kg}$, 但是其口服利 用度较低, 仅为 $3 \%{ }^{[94]}$.
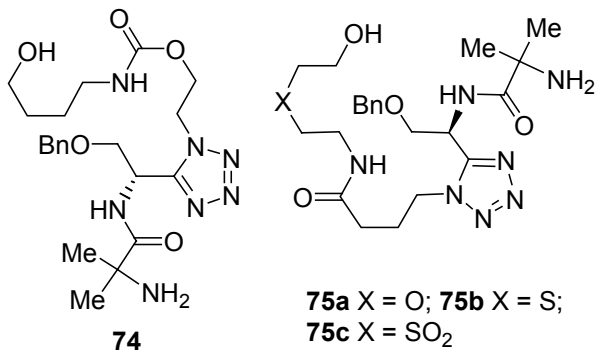

腈基四唑类化合物 76 具有良好促生长激素分泌活 性, 在重麻醉的小鼠实验模型中 $\mathrm{ED}_{50}$ 值和 $\mathrm{EC}_{50}$ 值分别 为 $8.5 \mu \mathrm{mol} / \mathrm{L} / \mathrm{kg}$ 和 $30 \mathrm{nmol} / \mathrm{L}$, 且具有较高的生物口服 利用度 $(56 \%)^{[95]}$. 与之相比，其类似物 77 的口服利用度 只有 $24 \%$, 但促生长激素分泌活性 $\left(\mathrm{EC}_{50}=0.4 \mathrm{nmol} / \mathrm{L}\right)$ 是 化合物 76 的 10 倍, 这为新的促生长激素分泌药物的开 发提供了基础 ${ }^{[96]}$.

\section{8 抗氧化类四唑类化合物}

人体新陈代谢过程中产生的以活性氧和活性氮为 典型代表的自由基可通过多种代谢途径产生有害物质, 


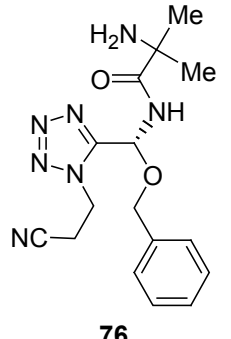

76

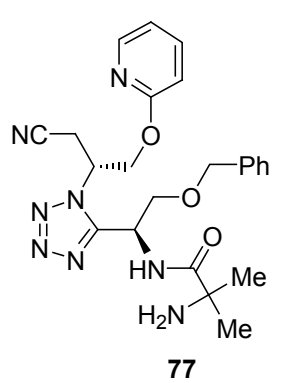

77
引起不同的健康问题如衰老、肿瘤及许多神经退行性疾 病等. 因此消除过多的氧化自由基, 提高机体抗氧化能 力以解决老化衰退相关的疾病日益成为重要的研究课 题之一.

研究表明吲哚-3-丙酰胺和 2-苯基吲哚类化合物具 有显著的抗脂质过氧化作用, 且抗氧化活性强于褪黑激 素 ${ }^{[97]}$. 引入四唑环片段的吲哚类化合物 78 具有较强抗 氧化和自由基清除作用, 通过抑制脂质过氧化产物含 量、增强抗氧化酶活性和诱导 GSH 的合成来抑制氧化 应激反应的发生. 四唑环和吲哚环的同时存在使其抗氧 化活性显著增强 ${ }^{[98]}$.

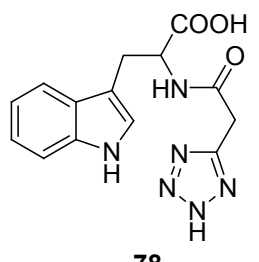

78

$\alpha$-硫辛酸(LA)在缺血性再灌注损伤、神经变性、糖 尿病、及放射性损伤引起的氧化性应激模型中具有抗氧 化活性. 因此它可用于各种治疗途径, 但是 LA 需要在 高浓度下才能发挥作用. 含有酰胺基的硫辛酸衍生物的 抗氧化活性要比其本体高, 用四唑环替代酰胺片段的化 合物 79, 因四唑环和邻苯二酚的协同作用, 抗氧化活性 显著提高 ${ }^{[99]}$.<smiles>Oc1ccc(CCn2nnnc2CCCCC2CCCC2)cc1O</smiles>

此外, 四唑类化合物 80 具有较高的抗氧化活性, 其 $\mathrm{IC}_{50}$ 值为 $0.14 \mathrm{mg} / \mathrm{mL}$, 活性强于没食子酸 $\left(\mathrm{IC}_{50}=0.83\right.$ $\mathrm{mg} / \mathrm{mL}$ ). 研究还发现该化合物对人体淋巴细胞无毒副 作用并且无遗传毒性 ${ }^{[100]}$.

\section{9 抗动脉弹样硬化类四唑类化合物}

动脉溇样硬化是缺血性心脑血管疾病的病理基础, 严重影响供血器官的血液供应并引发血栓性疾病, 对中 老年人健康造成威胁. 四唑类化合物对高脂蛋白、胆固

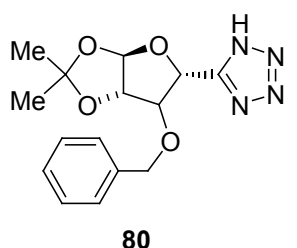

醇的合成具有抑制作用, 在预防和治疗动脉樔样硬化等 高血脂病症表现出巨大潜力.

临床上烟酸(Nicotinic Acid)常用于治疗血脂异常和 心血管疾病, 疗效高于其他药物. 但是烟酸的刺激性比 较大, 具有面部潮红、肝毒性、皮肤癌痒和胃肠不适等 副作用. 化合物 81a 是一种新型的 G-蛋白偶联受体激动 剂, 可有效降低游离脂肪酸含量且无潮红等不良反应, $\mathrm{IC}_{50}$ 值达到 $0.87 \mu \mathrm{mol} / \mathrm{L}^{[101]}$. 虽然在脂质异常患者的 II 期的试验结果令人失望, 但临床 I 期的其它适应症将继 续开发. 其类似物 $81 \mathrm{~b}$ 是一种更有效的 G-蛋白偶联受体 激动剂, $\mathrm{IC}_{50}$ 值达到 $0.09 \mu \mathrm{mol} / \mathrm{L}$, 活性与烟酸相近 $\left(\mathrm{IC}_{50}=0.06 \mu \mathrm{mol} / \mathrm{L}\right)$. 高效的降脂效果以及良好的药代 动力学分布表明该化合物在治疗脂质异常方面有进一 步的开发前景 ${ }^{[102]}$.

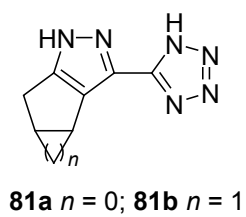

抑制胆固醇酯转移蛋白的活性对预防和治疗动脉 强样硬化非常重要. 化合物 82 具有较强胆固醇酯转移 蛋白抑制作用, 尤其是左旋体的平均活性值 $\left(\mathrm{IC}_{50}=230\right.$ $\mathrm{nmol} / \mathrm{L})$ 高于其右旋体 $\left(\mathrm{IC}_{50}=870 \mathrm{nmol} / \mathrm{L}\right)$. 其中左旋 $R$ 构型的活性最高, $\mathrm{IC}_{50}$ 值低至 $143 \mathrm{nmol} / \mathrm{L}$, 但其水溶性较 差 $(<10 \mathrm{ng} / \mathrm{mL})$, 在体内的清除率较低 ${ }^{[103]}$.

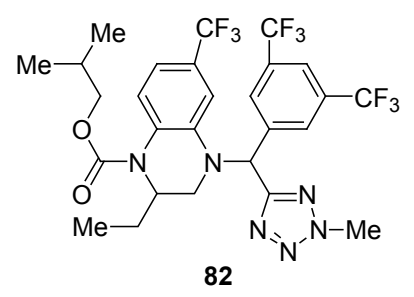

\subsection{0 抗糖尿病类四唑类化合物}

糖尿病的高发病率、患者趋于低龄化以及多种复杂 并发症的出现, 引起了全世界的极大关注, 众多相关工 作致力于降血糖药物的研发. 研究表明, 四唑类化合物 在抑制糖代谢酶以及提高胰岛素分泌方面具有较大前 景, 为新型高效抗糖尿病药物的研发提供选择.

吡咯基羧酸衍生物对醛糖还原酶具有抑制作用, 利 用四唑与羧基的生物等排性，可将四唑替代羧基期望得 
到新的醛糖还原酶抑制剂. 虽然化合物 83 对醛糖还原 酶的抑制低于相应的羒酸衍生物 $\left(\mathrm{IC}_{50}<10 \mu \mathrm{mol} / \mathrm{L}\right)$, 但 是其亲脂性是羧酸类似物的 10 倍以上, 总体效果更 好 ${ }^{[104]}$.

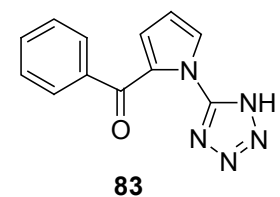

蛋白酪氨酸磷酸酶 $1 \mathrm{~B}$ 在胰岛素信号传导中具有十 分重要的作用, 已成为治疗糖尿病的重要靶点. 研究证 明, 噻吩类化合物对蛋白酪氨酸磷酸酶 $1 \mathrm{~B}$ 具有抑制性. 用四唑环取代羧基后, 化合物 84 对蛋白酪氨酸磷酸酶 $1 \mathrm{~B}$ 的抑制作用减弱了 $\left(K_{\mathrm{i}}=270 \mu \mathrm{mol} / \mathrm{L}\right)$. 为提高活性特 对其结构进行修饰得到化合物 85 , 该化合物的活性明 显提高, 是化合物 84 的 160 倍 $\left(K_{i}=1.3 \mu \mathrm{mol} / \mathrm{L}\right)$. 此外, 与噻吩类本体相比, 引入四唑基的化合物还具有代谢稳 定、渗透率高的优点 ${ }^{[105]}$.

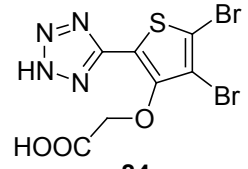

84

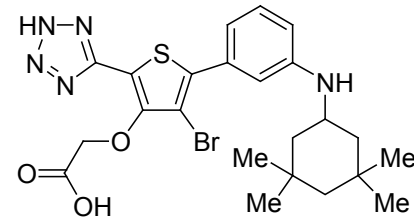

85
此外, 硬脂酰基-辅酶 a 脱氢酶 1 (SCD1)抑制剂对 II 型糖尿病具有具有较好的治疗潜力, 但是临床前期对 皮肤和眼睛组织的毒副作用限制了其发展. 为开发低毒 性的 SCD1 抑制剂设计合成得到的化合物 86 具有较好 的肝脏定向给药和良好的药代动力学性质, 其 $\mathrm{IC}_{50}$ 值低 至 $1 \mathrm{nmol} / \mathrm{L}$, 已经进入临床研究 ${ }^{[106]}$. 研究表明, 四唑羒 基和芳基部分是其良好生物活性的重要基团, 因此众多 工作致力于二者之间桥链部分的研究 ${ }^{[107,108]}$.

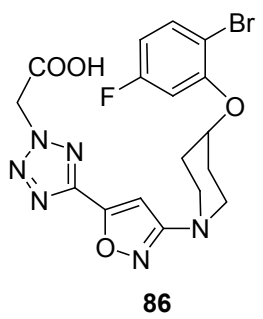

\section{3 农业领域}

唑类农药以其优良的除草活性、高效的植物调节作 用、低毒的杀菌和杀虫活性备受农业科技工作者关注， 克服了传统农药对人类健康和环境安全造成的种种威 胁, 在农业领域得到广泛应用. 四唑类化合物作为农药
的研发具有较大潜力, 成为新型绿色高效农药研发的重 点方向之一.

\section{1 四唑类化合物作为除草剂}

近年来，随着对除草剂标准要求的不断提高，唑类 除草剂因其优越的生物活性和环保低毒的特点而引起 农业工作者的广泛关注. 四唑类化合物作为除草剂的研 究工作众多, 是新型高效绿色农药研制的重要方向之

磺酰腿类除草剂具有超高活性、低剂量、低毒性、 高选择性对环境友好性等众多优点, 被公认为高效、环 保型农药. 对其结构进行修饰，引入四唑基团得到的四 唑嘧磺隆 4 对稻草植物具有高效快速的除草活性，而在 水稻体内可迅速分解为无除草活性的代谢产物，表现出 高效的选择性. 并且在水介质中, 四唑嘧磺隆在微生物 等作用下水解为磺酰胺和嘧啶胺, 具有低毒和环保 性 $^{[109]}$

将腿类化合物与四唑键连得到的四唑类化合物 87 具有除草活性, 其中 87b 的除草效果最好, 浓度为 100 $\mathrm{mg} / \mathrm{L}$ 时对稗草抑制率可达 $89.6 \%{ }^{[110]}$. 此外，结构相似 的含有梄键结构的四唑类衍生物 88 对油菜和稗草也具 有一定的除草活性，在 $100 \mu \mathrm{g} / \mathrm{mL}$ 浓度下对油菜的除草 活性较稗草强, 其中化合物 $\mathbf{8 8 b}$ 对油菜的抑制率高达 $87.5 \%^{[111]}$.<smiles>[R]c1ccc(NC(=O)Nc2nnn[nH]2)cc1</smiles>

$87 a \mathrm{R}=\mathrm{Me} ; 87 \mathrm{~b} \mathrm{R}=\mathrm{Cl}$

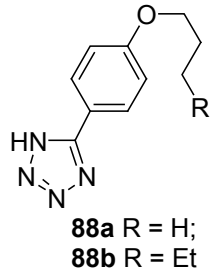

88a $R=H ;$
88b R = Et
四唑啉酮类化合物具有优良的除草活性，颇受农药 科研工作者的关注. 虽然至今开发成商品化的品种只有 化合物 89, 但该类结构的除草剂却给新农药设计开发 带来新的启迪. 含有肜醚结构的四唑啉酮类化合物 90 具有良好的除草活性，在 $500 \mathrm{~g} / \mathrm{hm}^{2}$ 剂量下，可有效防 治稗草、异型莎草、萤萄等恶性杂草. 基于化合物 $\mathbf{9 0}$ 的母体结构, 直接将肜醚四唑啉酮部分与苯环相连得到 的化合物 91 对狗尾草、芥菜、反枝苋、小菉、稗草等 杂草均具有一定的除草活性. 芳基为低级烷烃或烯烃替 代时除草活性大大减弱或消失 ${ }^{[112]}$.

\section{2 四唑类化合物作为植物生长调节剂}

杂环类羧酸衍生物具有广泛的生物活性, 尤其在植 物生长调节方面效果显著. 在杂环多酸中引入四唑片段 等排其结构中的羧基得到一系列新型、高效、低毒和绿 
<smiles>CCN(C(=O)n1nnn(-c2ccccc2Cl)c1=O)c1ccccc1</smiles>

89
90<smiles>CCCN(C(=O)n1nnn(CC(C)=NOCc2ccccc2)c1=O)c1ccccc1</smiles><smiles>CO/N=C(/C)Cn1nnn(-c2ccc(Cl)cc2)c1=O</smiles>

91

色植物生长调节剂, 为新型植物生长调节剂研发提供了 新的研究方向.

硫代四唑类化合物 92 在低浓度剂量下对油菜籽和 小麦的生长具有较好的促进作用. 在 $1 \mathrm{mg} / \mathrm{L}$ 的剂量下, 对油菜的促进生长率为 $67.2 \%$, 弱于参比农药吅哚乙酸. 但是在 $0.1 \mathrm{mg} / \mathrm{L}$ 剂量下, 该化合物对小麦的生长促进活 性(79.3\%) 强于吲哚乙酸 $(46.5 \%)^{[113]}$.

三唑甲硫基四唑(93)对单子叶植物小麦幼苗具有明 显的生长调节作用. 研究表明, 在 $10 \mathrm{mg} / \mathrm{L}$ 剂量时其对 小麦幼苗的生长抑制作用较为明显, 随浓度的降低其生 长促进活性显著增强, 当浓度降低至 $0.001 \mathrm{mg} / \mathrm{L}$ 时生长 促进活性最好, 优于吲哚乙酸 ${ }^{[14]}$.

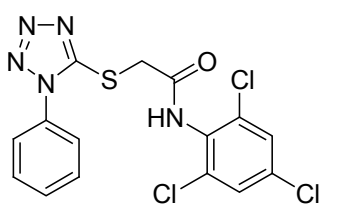

92

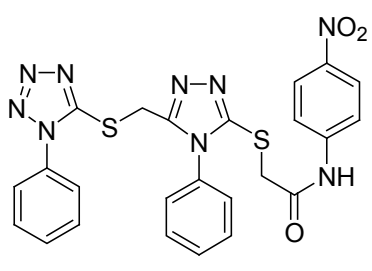

93

\section{3 四唑类化合物作为杀菌剂和杀虫剂}

近年来, 唑类杀菌剂如硅氟唑(Simeconazole)、苯菌 灵 (Benomyl) 以及杀虫剂如氟虫腈 (Fipronil)、三唑磷 (Triazophos)等具有高效、低毒、对人畜安全的优点，广 泛用于农业生产. 然而病菌以及害虫的高变异性和耐药 性的产生, 给农业丰收带来严重威胁, 急需开发新型结 构的农用杀菌剂、杀虫剂。

四唑啉酮类化合物除了具有良好的除草活性外，也 具有很好的杀虫活性, 引起农药工作者的广泛关注. 化 合物 94 对朱砂叶螨具有很强的杀虫活性. 将 1,3,4-噻重 氮与四唑啉酮结合后的化合物具有新的生物活性的化 合物 94. 体外生物活性显示, 化合物 94 和 95 对小麦、 油菜等的根和茎均表现出不同程度的抑制活性. 然而进 一步的温室试验中, 二者的除草活性均消失了, 却显示 出杀虫作用. 在 $250 \mathrm{mg} / \mathrm{L}$ 的剂量下, 对朱砂叶螨具有较 强的杀虫活性 ${ }^{[115,116]}$.

此外, 金属锡的四唑乙酸类络合物 96 也可作为杀 菌剂用于农业生产, 且其抗菌谱较宽. 在 $50 \mu \mathrm{g} / \mathrm{mL}$ 剂量<smiles>C=CCn1nnn(-c2ccccc2Cl)c1=O</smiles><smiles>[R]CSc1nnc(Cn2nnn(-c3ccc(Cl)cc3)c2=O)s1</smiles>

下，对索兰尼链格孢、玉米赤霉菌、灰斑病菌等均具有 较好杀菌活性 ${ }^{[117]}$.<smiles>CCCCC(CCCC)(OC(=O)Cn1cnnn1)OC(=O)Cn1cnnn1</smiles>

\section{4 材料领域}

四唑环的多氮富电子共轭体系以及很强的分子内 电子转移等特性使四唑类化合物表现出许多独特的性 能，备受材料工作者的青睐，广泛应用于材料领域的众 多方面. 目前四唑类化合物作为新型材料的研究已涉及 到含能材料、燃料电池材料、光敏材料以及金属抗腐蚀 等领域，展现出巨大的研发价值和宽广的应用前景.

\section{1 四唑类含能材料}

新型含能材料的开发是材料化学领域的一个薮新 的研究分支，是基于对现有传统使用材料进行更新换代 的需要而逐步发展起来的. 新型含能材料以高能量密 度、热稳定性高、操作安全性高、制备途径简单经济等 特点而受到广泛关注 ${ }^{[18]}$. 由于多氮唑类杂环化合物含 氮量高, 分子中含有 $\mathrm{N}-\mathrm{N}, \mathrm{N}-\mathrm{C}$ 键等高能量的化学键, 具有较高的生成焓、密度和气体生成量, 较容易达到零 氧平衡以及分解产物污染程度低等优点. 因此, 这类化 合物成为当前新型含能材料的研究热点之一, 在炸药、 固体推进剂和烟火药等领域显示出良好的应用前景. 四 唑具有高含氮量以及易于金属离子配位的特点, 使得四 唑类含能盐及含能配合物引起人们极大的关注.

\subsection{1 四唑盐类含能材料}

含能盐是一类高氮含量、高密度、高生成焓和氧平 衡较高的含能材料. 五元富氮杂环类化合物作为合成离 子盐的前体之所以日益引起人们关注, 主要是因为四唑 类化合物既可作阳离子又可作阴离子，大大丰富了含能 盐的种类，为新型优良的含能盐的开发提供了基础. 目 前众多研究工作致力于该领域，众多研究成果已广泛用 于军事和民用航天领域.

二氨基四唑的含氮量高达 $84 \%$, 对高能量密度材料 
的开发具有十分重要的意义. 化合物 97 分别是 1,5-二氨 基四唑的硝酸盐、高氯酸盐、二硝铵盐或叠氮盐的形式, 它们的爆压值介于 TNT (20.6 GPa) 和 RDX (34.4 GPa)之 间, 爆速值介于硝化甘油(7610 m•s$\left.{ }^{-1}\right)$ 和 RDX (8750 m• $\mathrm{s}^{-1}$ )之间. 另外，1,5-二氨基四唑 4-位氮被质子化后可与 去质子化的酚羟基形成较稳定的盐, 对各种摩擦和撞击 均不敏感, 但是在加热条件下易分解, 同时伴随有大量 气体和热量的释放 ${ }^{[119]}$.

$$
\begin{aligned}
& \text { 97a, } \mathrm{R}=\mathrm{H}, \mathrm{X}=\mathrm{NO}_{3} ; \\
& \text { 97b, } \mathrm{R}=\mathrm{H}, \mathrm{X}=\mathrm{ClO}_{4} ; \\
& \text { 97c, } \mathrm{R}=\mathrm{Me}, \mathrm{X}=\mathrm{NO}_{3} ; \\
& \text { 97d, } \mathrm{R}=\mathrm{Me}, \mathrm{X}=\mathrm{N}^{\mathrm{N}}\left(\mathrm{NO}_{2}\right)_{2}
\end{aligned}
$$

以上形成含能盐的小阴离子如 $\mathrm{ClO}_{4}^{-}, \mathrm{NO}_{3}^{-}$和 $\mathrm{N}\left(\mathrm{NO}_{2}\right)_{2}^{-}$与四唑环形成的含能盐在作为火箭推进剂时 存在一个严重的缺点, 即小阴离子携带的氧不能把阳离 子充分氧化. 而化合 98 中含有四硝基铝的 12 个氧可以 将 1-乙基-4,5-二甲基四唑阳离子完全氧化, 进而爆发出 更大能量 ${ }^{[120]}$.

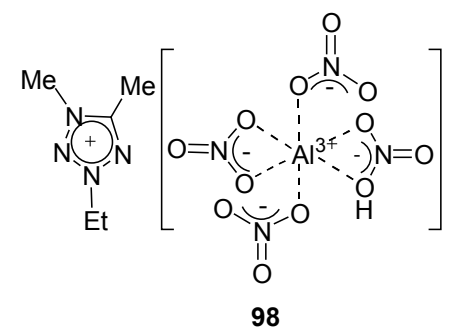

四唑类化合物作为阴离子时主要与过渡金属阳离 子形成含能盐，5-亚甲基二四唑与铜、铅形成的含能盐 99, 可作为 $\mathrm{CMDB}$ 的有效含能助燃剂 ${ }^{[121]}$. 四唑环上引 入硝基后其密度和能量将大幅提高, 5-硝基四唑的录盐 或银盐 100 可作为起爆药而应用于炸药领域. 同时, 硝 基的引入大大增加了其酸性 $\left(\mathrm{p} K_{\mathrm{a}}=0.8\right)$, 因此硝基四唑 可与碱性唑类化合物氨基四唑反应形成含能盐, 为新型 高效能起爆药的研发提供基础 ${ }^{[122]}$.
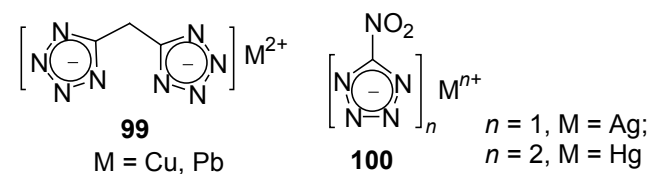

\subsection{2 四唑配合物类含能材料}

含能配合物具有优越的强烈爆炸功能，在起爆药、 固体推进剂催化剂等领域得到了广泛应用. 作为含能配 合物的配体必须满足 2 个条件: 一是含碳氢量少且含氮 量高, 即具有较高的正生成焓, 易达到氧平衡; 二是至 少含一个能提供孤对电子的配位原子, 如 $\mathrm{N}, \mathrm{O}, \mathrm{S}$ 等杂
原子 ${ }^{[123]}$. 四唑环上的 $\mathrm{N}$ 原子都含有孤对电子，具有很 强的配位能力, 是高能可靠、安全钝感、绿色环保的含 能配合物开发研究的热点.

高氯酸·四氨・双(5-硝基四唑)合钴(III) (101，BNCP) 具有安全性好、耐热性好、起爆性能好的特点, 是一种 性能优异的新型起爆药，可以实现 $\mathrm{BNCP}$ 雷管的单一装 药, 能够部分代替叠氮化铅、斯蒂芬酸铅或 CP 用于激 光起爆器、点火元件以及多种雷管中 ${ }^{[124]}$.

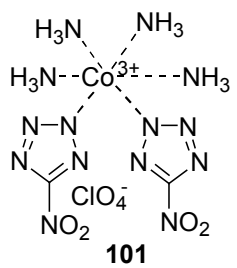

氨基四唑类化合物是构建配合骨架的良好供电子 体，相关研究文献工作众多. 对甲苯磺酸·二水・双(5-氨 基四唑)合铜(II) 102 具有较高的热稳定性，其热分解过 程需经历三个阶段, 分解温度范围为 $163.8 \sim 600{ }^{\circ} \mathrm{C}$, 有 望成为新型高氮含能材料 ${ }^{[125]}$.<smiles>Cc1ccc(O[C@](O)(OS(=O)(=O)c2ccc(C)cc2)n2nnnc2[N+](=O)[O-])cc1</smiles>

化合物 2,4,6-三硝基间苯二酚 $\left(\mathrm{H}_{2} \mathrm{TNR}\right)$ 是一种广为 人知的多氮强酸性化合物，与 1,5 -二氨基四唑(DAT)和 镉形成配合物 103 , 具有较高的生成焓和热稳定性, 有 望成为含能材料的候选化合物 ${ }^{[126]}$. 此外, 1,2-双四唑乙 烷 $\left(\mathrm{H}_{2} \mathrm{BET}\right)$ 不仅氮含量高、化学稳定性好, 而且具有灵 活多样的配位方式. 1,2-双四唑乙烷可与碱土金属钡和 锶络合形成含能配合物多聚体 104, 热稳定性高达 350 ${ }^{\circ} \mathrm{C}$, 在火箭推进剂领域具有进一步的开发价值 ${ }^{[127]}$.

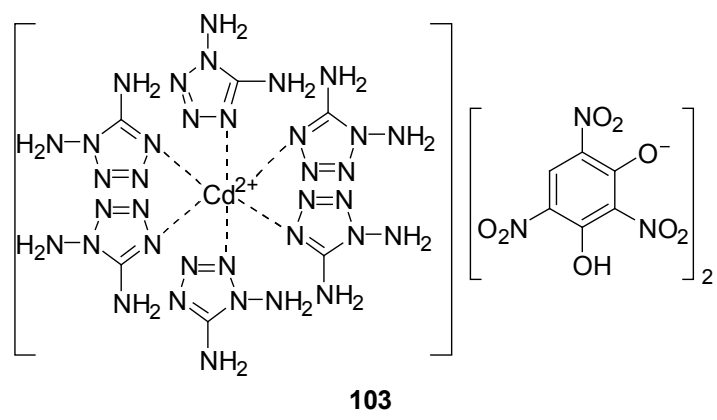

\section{2 四唑类燃料电池材料}

高质子电解质膜具有近乎零发射、高能量密度、无 腐蚀液的特点，备受关注。氟化磺酸膜(如 Nafion 和 


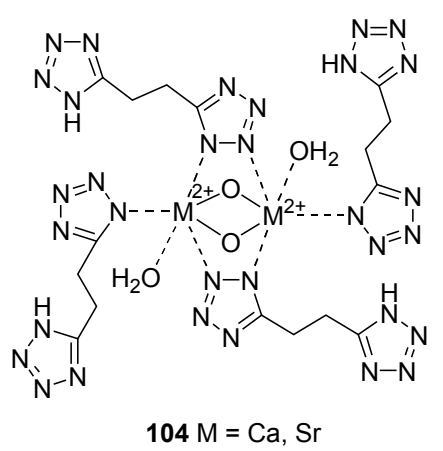

Dow) 是最常用的质子交换膜, 但对水具有高度的依赖 性, 不适用于温度和压力高于水沸点以上的环境. 近年 来, 多聚杂环类无水质子导电材料如三唑、咪唑和四唑 等通过氢键网状结构的快速上下振动的动力进行质子 自递反应和大范围质子扩散, 在燃料电池领域显示出巨 大的应用潜力 ${ }^{[28,129]}$.

基于四唑形成的聚合物如聚 5-乙烯基四唑(PVT)是 一类热稳定性高、溶解性好、导电性能高的无水质子传 导材料 ${ }^{[130,131]}$. 在 $120{ }^{\circ} \mathrm{C}$ 温度下, PVT 的质子电导率(约 $10^{-10} \mathrm{~S} \cdot \mathrm{cm}^{-1}$ ) 高于聚 4-乙烯基咪唑的电导率(约 $10^{7}$ $\left.\mathrm{S} \cdot \mathrm{cm}^{-1}\right)$. 磷酸掺杂的聚 5-乙烯基四唑并丙烯腈 $[105$, $\mathrm{P}(\mathrm{VT}-\mathrm{co}-\mathrm{AN})]$ 在一定温度下电导率与膜的组成有关, 当 聚合物分子质量较低且四唑和磷酸的相对含量较高时 其质子传导率较高. 室温下, 分子质量为 $8 \times 10^{4}$ 的 $\mathrm{P}(\mathrm{VT}-\mathrm{co}-\mathrm{AN}) / 1.0 \mathrm{H}_{3} \mathrm{PO}_{4}$ 质子传导膜的电导率为 $10^{-4}$ $\mathrm{S} \cdot \mathrm{cm}^{-1}$, 其质子电导率随温度和磷酸掺杂含量的增高而 升高.

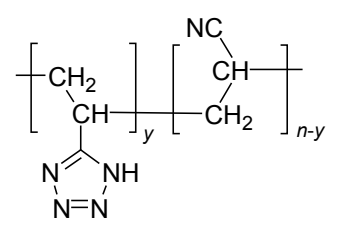

105

氨基四唑(ATet)具有较高的熔点 $\left(203{ }^{\circ} \mathrm{C}\right)$, 这使其 成为新型芳杂环唑类无水质子传导膜的研究热点. 化合 物 106 具有较好的质子导电性, 在 $150{ }^{\circ} \mathrm{C}$ 时其电导率为 $1.0 \mathrm{~S} \cdot \mathrm{cm}^{-1}$, 加入 $0.5 \mathrm{~mol}$ 酸液后其电导率可达到 19 $\mathrm{S} \cdot \mathrm{cm}^{-1}{ }^{[132]}$. (3-环氧乙基)丙基三甲氧基硅烷通过环氧基 开环引入氨基四唑得到化合物 107, 然后经过溶胶-凝 胶聚合作用形成四唑硅烷网状结构膜. 在 $150{ }^{\circ} \mathrm{C}$ 无水状 态下, 这种结构膜的质子传导率为 $10^{-4} \mathrm{~S} \cdot \mathrm{cm}^{-1}$. 有三氟 甲基磺酸(TA)掺杂时, 其质子传导率随酸和氨基四唑比 例的变化而不同. 在 $150{ }^{\circ} \mathrm{C}$ 温度下, TA/ATet 的比值为 0.5 时其质子传导率为 $2.0 \times 10^{-4} \mathrm{~S} \cdot \mathrm{cm}^{-1}$, 当 $\mathrm{TA} / \mathrm{ATet}$ 的比 值升至 1.0 时其电导率则增加到 $1.8 \times 10^{-3} \mathrm{~S}^{\circ} \mathrm{cm}^{-1}[133]$.<smiles>O=C(Nc1nnn[nH]1)c1cc(C(=O)Nc2nnn[nH]2)cc(C(=O)Nc2nnn[nH]2)c1</smiles><smiles>CO[Si](CCCOCC(O)CNc1nnn[nH]1)(OC)OC</smiles>

氨基四唑可对聚乙烯基苄氯进行修饰得到新的质 子传导膜聚乙烯基芐氨基四唑 108, 在有三氟甲基磺酸 (TA)掺杂的情况下热稳定性高达 $200{ }^{\circ} \mathrm{C}$ 以上. TA/ATet 为 2.5 时 PVBCATET-TA $_{2.5}$ 的最大质子电导率值是 0.01 $\mathrm{S} \cdot \mathrm{cm}^{-1}\left(150{ }^{\circ} \mathrm{C}\right)$, 而且傅里叶变换红外光谱表明质子是 由酸向四唑环传导的 ${ }^{[134]}$. Nafion 是一类最常用于燃料电 池的质子交换膜，浸入热稳定性高、低挥发性的氨基四 唑浓缩液中其膨胀系数和热稳定性将增大, 并且在甲醇 中的浸透性会降低. 在无水状态下, Nafion-ATet 体系的 最高质子传导率为 $1.6 \times 10^{-4} \mathrm{~S} \cdot \mathrm{cm}^{-1}\left(180{ }^{\circ} \mathrm{C}\right)^{[135]}$.

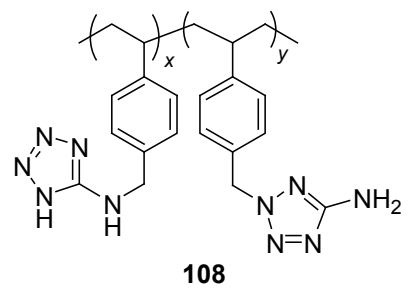

\section{3 四唑类化合物作为光敏材料}

四唑类化合物与过渡金属形成的络合物具有多种 电荷转移形式如配体 $\rightarrow$ 配体、配体 $\rightarrow$ 金属以及金属 $\rightarrow$ 配 体, 在近紫外区四唑类络合物具有很强的特殊的荧光性 质. 因此, 这些金属配合物有望成为新型光学材料如发 光二极管、电致发光显示器等, 具有很大的开发前景.

吡唑四唑类化合物与过渡金属锌和锰离子以 $2: 1$ 的比例形成的络合物 109. 在室温条件下, 电荷在配体 之间的传递使二者的最大发射波长分别为 $383 \mathrm{~nm}$ $\left(\lambda_{\mathrm{ex}}=309 \mathrm{~nm}\right)$ 和 $411 \mathrm{~nm}\left(\lambda_{\mathrm{ex}}=311 \mathrm{~nm}\right)$, 呈现出很强的 蓝色荧光, 具备开发为光敏材料的潜力 ${ }^{[136]}$.

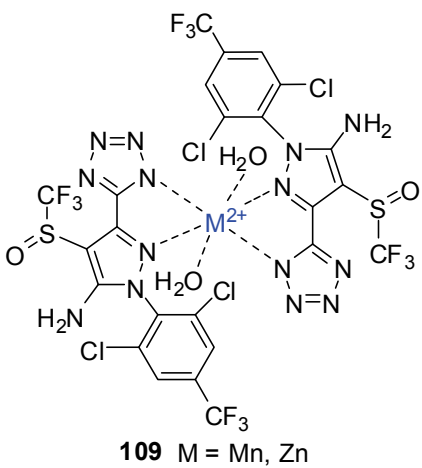


吡啶四唑作为配体参与络合的一价铜络合物 $\mathbf{1 1 0}$ 中, 电荷由金属向配体转移使该络合物在 $495 \mathrm{~nm}$ 处具 有较强吸收, 发出明亮的蓝绿色荧光. 同时该络合物的 发射荧光强度对 $\mathrm{O}_{2}$ 浓度十分敏感, 复合材料 $[\mathrm{Cu}(\mathrm{POP})-$ $(\mathrm{PTZ})] \mathrm{BF}_{4} / \mathrm{MCM}-41$ 在 $20 \mathrm{mg} / \mathrm{g}$ 的负载水平下就具有很 强的敏感性 $\left(I_{0} / I_{100}>11\right)$ 和较短的反应时间 $(t<5 \mathrm{~s})$, 并且 $\mathrm{Cu}(\mathrm{I})$ 无毒, 对人体及环境十分安全, 应用前景巨大 ${ }^{[137]}$.

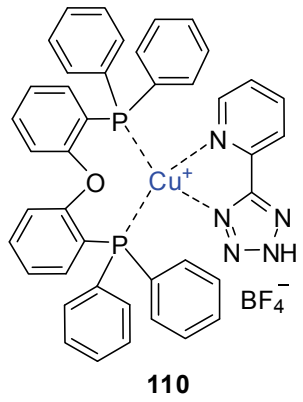

吡啶四唑的激发波长范围在 $250 \sim 300 \mathrm{~nm}$ 之间，荧 光较弱, 与金属镉易形成络合物后由于电荷由配体向金 属离子转移 $\left(\pi_{5 z} \rightarrow 5 \mathrm{~s}\right)$, 使该类络合物在 417 到 $457 \mathrm{~nm}$ 之 间具有较强的苂光性质, 尤其是 4-吡啶四唑与镉的络合 物 111 具有三重态寿命周期, 是目前在二价镉配合物中 观测到的寿命周期最长的化合物 ${ }^{[138]}$.

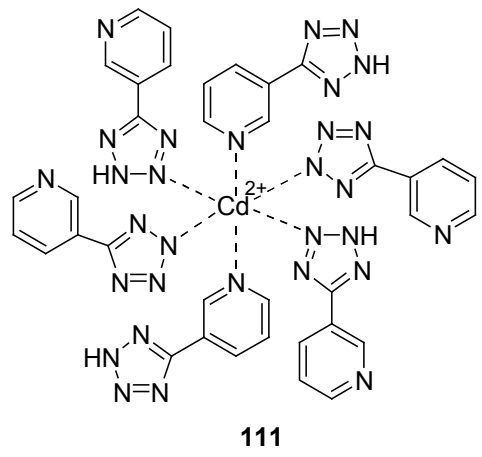

\section{4 四唑类金属缓蚀材料}

金属腐蚀易引发安全事故, 给国民经济造成严重损 失. 含 $\mathrm{O}, \mathrm{N}, \mathrm{S}$ 等原子的有机缓蚀剂可通过与金属表面 的金属离子或原子形成络合物从而达到缓蚀效果 ${ }^{[139,140]}$. 与无机缓蚀剂如铬酸盐、重铬酸盐相比, 杂环类有机缓 蚀剂具有低毒和环境友好的优点.

金属铜及其合金具有良好的导电性、可加工性以及 抵抗性而广泛应用于电子工业领域. 铜及其合金对空气 和很多化学物质有抵抗力, 氯离子和酸、碱性介质比较 敏感 ${ }^{[141]}$. 四唑类化合物 112 (ATP)对铜的腐蚀具有较强 的抑制作用 ${ }^{[142,143]}$. 在 $3.5 \%$ 氯化钠溶液中, $5 \mathrm{mmol} / \mathrm{L}$ ATP 对金属铜的腐蚀抑制率高达 $99.3 \%{ }^{[144]}$. 此外, 在 $0.5 \mathrm{~mol} / \mathrm{L}$ 的盐酸溶液中, $5 \mathrm{mmol} / \mathrm{L} \mathrm{ATP}$ 对金属铜的腐蚀

抑制率也可达 $90 \%{ }^{[145]}$. 胍基四唑(113，GT)和巯基四唑 (114, MMT) 在 5\% $\mathrm{NaHCO}_{3}$ 碱性介质中对铜均有很好的 缓蚀作用. 当浓度为 $50 \mathrm{mg} \cdot \mathrm{L}^{-1}$ 时二者均达到最大缓蚀 效率 $(90 \%)$, 并且在 $30 \sim 60{ }^{\circ} \mathrm{C}$ 温度范围内, 两种缓蚀剂 的缓蚀效果随温度的升高而降低 ${ }^{[146]}$.

112<smiles>Nc1cccc(-c2nnn[nH]2)c1</smiles>

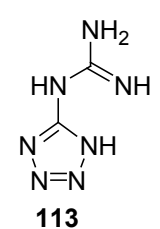

113

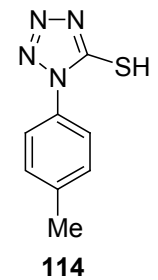

大多数四唑类化合物对金属铜及其合金都有一定 的抗腐蚀性能，但由于四唑环上取代基的不同对铜及其 合金的缓蚀能力而有所不同. 在 $0.1 \mathrm{~mol} / \mathrm{L} \mathrm{HNO}_{3}$ 溶液 中，对铜锌合金(7：3)腐蚀的抑制效率有如下顺序: 1-苯 基-5-巯基四唑 $>1$-苯基四唑 $>5$-氨基四唑 $>$ 四唑 ${ }^{[147]}$. 这四种化合物在 $1.0 \mathrm{~mol} / \mathrm{L}$ 盐酸介质中对金属铝也具有 防腐蚀性能，且其对铝防腐效率也遵循上述顺序 ${ }^{[148]}$.

碳钢因其良好实用性和机械性能，广泛应用于工业 制造中，盐酸等酸性介质是造成其严重腐蚀的重要因 素. 四唑鎓盐 115 通过大共轭体系与 $\mathrm{Fe}$ 原子的相互作用 生成络合物而覆盖在碳钢表面的活性位点，从而阻碍腐 蚀反应进行 ${ }^{[149]}$. ATP 除了对 $\mathrm{Cu}$ 有良好的缓蚀效果外, 对金属铁的缓蚀作用也非常显著. 在 $3.5 \%$ 的氯化钠溶 液中, ATP 通过与金属铁表面的 $\mathrm{Fe}^{2+}$ 形成络合物而达到 防蚀效果. 实验结果表明, ATP 对铁的均匀腐蚀和点蚀 均具有良好的抑制效果 ${ }^{[150]}$.

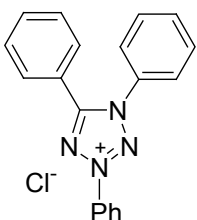

115

\section{5 四唑类催化剂}

四唑类化合物为催化剂具有稳定安全、催化活性 高、易于回收利用的特点，相关研究工作众多，可用于 催化着醛缩合、曼尼希和醛酤的 $\alpha$-氨基化等多种反 应 $^{[151]}$.

迈克尔加成(Michael addition)是有机合成中一种非 常重要的增长碳链的反应. 羰基化合物与 $\alpha, \beta$-不饱和硝 基烯烃的反应是迈克尔加成的一个典型，当其产物为手 性分子时，需选择合适的催化剂以满足合成需求. 吡咯 烷基四唑 116 具有较高的催化活性和立体选择性，作为 不对称合成有机催化剂引起人们越来越多的关注. 在各 种醇类溶剂条件下，2-吡咯烷基四唑对羰基化合物与硝 
基烯烃的不对称迈克尔加成反应的催化活性和空间选 择性均高于脯氨酸 ${ }^{152]}$. 2-苯并吡咯烷基四唑 117 对以 $\alpha, \beta$-不饱和醛和硫叶立德为原料合成含三元环的不对称 醛的反应具有高度的催化立体选择性 $(99 \% e e)^{[153]}$.

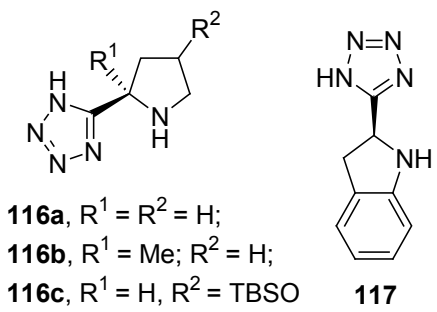

2-吡咯烷基四唑还可作为醛酮化合物 $\alpha$-位不对称 氧化制备 $S$-差年醛(酮)反应的催化剂. 在反-2-对甲基苯磺 酰-3-苯基环氧甲胺氧化环己酮的反应中, 其催化活性 优于脯氨酸. 当吡咯环基 2-位有甲基取代时, 催化效率 和对应选择性均增强 ${ }^{[154]}$. 此外, 三氟乙醛的半缩醛与 芳基甲基酮可在 2-吡咯烷基四唑的选择性催化下反应 制备 $\beta$-差基芳酮, ee 值高达 90\% ${ }^{[155]}$. 在亚硝基苯作用 下, 醛的 $\alpha$-差氨基化或氨氧基化不对称合成也可用吡咯 烷基四唑作为选择性催化剂, 产率高达 96\%, 其中以羟 氨基化化合物为主 $(81 \% e e)$. 吡咯环 4 位取代的四唑化 合物 $116 \mathrm{c}$ 的不对称催化活性与之相当 $(93 \% e e)^{[156]}$.

重金属钯是一种广泛使用的催化剂，与四唑形成的 化合物 118 具有结构稳定、催化活性高和回收利用度好 的优点. $1 \mathrm{~mol} \%$ 化合物 118 即可有效催化 Heck 反应, 催 化产率最高可达 $98 \%$ 之间 ${ }^{[157]}$. 同时该催化剂对 Suzuki 偶联反应也具有很好的催化效果, 特别是选择乙醇或二 甲基甲酰胺的水溶液中, 其平均催化产率高于 $90 \%{ }^{[158]}$.

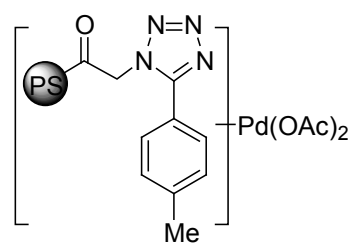

118

\section{5 结语}

综上所知, 四唑类化合物的合成及其应用研究工作 十分活跃, 取得许多重要成果. 通过构筑四唑环是制备 四唑类化合物的重要途径, 已获得许多成熟、简便的方 法, 但是开发更加安全高效、绿色经济的新合成方法仍 是化学工作者所面临的重要课题. 新型高效催化剂的开 发、合成原料的拓宽以及新合成技术的出现将推动四唑 类化合物在有机合成领域的蓬勃发展, 为构筑具有新型 化学结构的四唑类化合物开辟出更多条件温和、效率 高、选择性好新途径. 四唑类化合物在众多医学课题方
面显示出独特的优势, 特别是在抗高血压和抗菌领域应 用潜力巨大，由此不难预料，利用四唑环生物电子等排 体特性对现有药物进行结构修饰或以四唑环为基体构 建全新结构的四唑类药物将可能成为医药领域的新方 向. 在农药领域, 四唑类除草剂和杀虫剂以其低毒、高 效、无污染等优点受到广泛关注, 随着绿色农药概念的 提出以及四唑类农药的显著潜在优势, 四唑类化合物将 是农药领域的重要研发方向之一. 在材料领域, 四唑类 化合物仍将是追求高能量密度、强热稳定性、高操作安 全性等特点的含能材料领域的研发热点和重点, 在炸 药、固体推进剂等领域必将取得更多突破性进展; 此外, 四唑类金属防腐剂和催化剂因具有高效、绿色环保的优 点在化学化工生产以及设备维护方面表现出显著优势, 随着研究工作开展, 四唑类化合物应用也将向燃料电池 和光敏材料领域更进一步延伸拓展.

我们深信, 随着四唑类化合物研究工作的深入以及 现代技术手段如计算机辅助和仿真模拟技术的迅猛发 展、结构和机制等数据库的不断完善, 对四唑类化合物 的合成及应用研究必将吸引更多科学工作者的关注, 四 唑类化合物必将为社会的进步与发展发挥积极作用.

\section{References}

[1] Cui, S.-F.; Wang, Y.; Lv, J.-S.; Damu, G. L. V.; Zhou, C.-H. Sci. Sin. Chim. 2012, 42, 110 (in Chinese).

(崔胜峰, 王艳, 吕敬松, Guri L. V. Damu, 周成合, 中国科学: 化 学, 2012, 42, 1105.)

[2] Cui, S.-F.; Zhou, C.-H.; Geng, R.-X.; Ji, Q.-G. Chin. J. Biochem. Pharm. 2012, 33, 311 (in Chinese).

(崔胜峰, 周成合, 耿蓉霞, 吉庆刚, 中国生化药物杂志, 2012, 33, 311.)

[3] Zhang, H.-Z.; Ji, Q.-G.; Geng, R.-X.; Zhou, C.-H. Chin. J. Org. Chem. 2012, 31, 1963 (in Chinese). (张慧珍, 吉庆刚, 耿蓉霞, 周成合, 有机化学, 2012, 31, 1963.)

[4] Wu, J.; Panek, J. S. Angew. Chem., Int. Ed. 2010, 122, 6301.

[5] Zhang, F.-F.; Gan, L.-L.; Zhou, C.-H. Bioorg. Med. Chem. Lett. 2010, 20, 1881.

[6] Zhang, F.-F.; Zhou, C.-H.; Yan, J.-P. Chin. J. Org. Chem. 2010, 30, 783 (in Chinese).

(张飞飞, 周成合, 颜建平, 有机化学, 2010, 30, 783.)

[7] Zhang, Y.-Y.; Zhou, C.-H. Bioorg. Med. Chem. Lett. 2011, 21, 4349.

[8] Wu, J.; Mi, J.-L.; Zhou, C.-H. Chin. Pharm. J. 2007, 42, 404 (in Chinese).

(吴俊, 米佳丽, 周成合, 中国药学杂志, 2007, 42, 404.)

[9] Cai, J.-L.; Li, S.; Zhou, C.-H.; Gan, L.-L.; Wu, J. Chin. J. New Drugs 2009, 18, 598 (in Chinese).

(蔡佳利, 李硕, 周成合, 甘淋玲, 吴俊, 中国新药杂志, 2009, 18, 598.)

[10] Fang, B.; Zhou, C.-H.; Rao, X.-C. Eur. J. Med. Chem. 2010, 45, 4388.

[11] Zhang, S.-L.; Damu, G. L. V.; Zhang, L.; Geng, R.-X.; Zhou, C.-H. Eur. J. Med. Chem. 2012, 55, 164.

[12] Meng, J.-P.; Geng, R.-X.; Zhou, C.-H.; Gan, L.-L.; Wu, J. Chin. J. New Drugs 2009, 16, 1505 (in Chinese). 
(孟江平, 耿蓉霞, 周成合, 甘淋玲, 吴俊, 中国新药杂志, 2009, 16,1505 .)

[13] Wang, Y.; Zhou, C.-H. Sci. Sin. Chim. 2011, 41, 1429 (in Chinese). (王艳，周成合，中国科学：化学, 2011, 41, 1429.)

[14] Zhou, C.-H.; Wang, Y. Curr. Med. Chem. 2012, 19, 239.

[15] Wang, X.-L.; Wan, K.; Zhou, C.-H. Eur. J. Med. Chem. 2010, 45, 4631

[16] Shi, Y.; Zhou, C.-H.; Zhou, X.-D.; Geng, R.-X.; Ji, Q.-G. Acta Pharm. Sin. 2011, 46, 798 (in Chinese). (时园, 周成合, 周向东, 耿蓉霞, 吉庆刚, 药学学报, 2011, 46, 798.)

[17] Shi, Y.; Zhou, C.-H. Bioorg. Med. Chem. Lett. 2011, 21, 956.

[18] Zhang, Y.-Y.; Mi, J.-L.; Zhou, C.-H.; Zhou, X.-D. Eur. J. Med. Chem. 2011, 46, 4391.

[19] Wang, Y.; Damu, G. L. V.; Lv, J.-S. Geng, R.-X.; Yang, D.-C.; Zhou, C.-H. Bioorg. Med. Chem. Lett. 2012, 21, 5363.

[20] Wang, X.-L.; Gan, L.-L.; Yan, C.-Y.; Zhou, C.-H. Sci. Sin. Chim. 2011, 41, 451 (in Chinese).

(王宪龙，甘淋玲，闰聪彦，周成合，中国科学：化学，2011，41, 451.)

[21] Rajasekaran, A.; Murugesan, S.; Kalasalingam, A. R. Arch. Pharm. Res. 2006, 29, 535.

[22] Kamble, R. R.; Biradar, D. B.; Meti, G. Y.; Taj, T.; Gireesh, T.; Khazi, I. A. M.; Vaidyanathan, S. T.; Mohandoss, R.; Sridhar, B.; Parthasarathi, V. J. Chem. Sci. 2011, 123, 393.

[23] Gutmann, B.; Roduit, J. P.; Dominique, R.; Kappe, C. O. Angew. Chem., Int. Ed. 2010, 49, 7101.

[24] Sureshbabu, V. V.; Nagendra, N.; Nagendra. G. J. Org. Chem. 2009, 74, 153.

[25] El Kaim, L.; Grimaud, L.; Patil, P. Org. Lett. 2011, 13, 1261.

[26] Saha, B.; Sharma, S.; Sawant, D.; Kundu, B. Tetrahedron 2008, 64, 8676.

[27] Wei, J.-J.; Wang, Y.; Wang, X.-L.; Zhou, C.-H.; Ji, Q.-G. Chin. Pharm. J. 2011, 46, 481 (in Chinese).

(魏金建, 王艳, 王宪龙, 周成合, 吉庆刚, 中国药学杂志, 2011, 46, 481.)

[28] Jin, T.; Kitahara, F.; Kamijo, S.; Yamamoto, Y. Tetrahedron Lett. 2008, 49, 2824.

[29] Aridoss, G.; Laali, K. K. Eur. J. Org. Chem. 2011, 31, 6343.

[30] Huang, J.-J.; He, X.-P.; Dong, Q.; Hu, J.; Shi, X.-X. Chin. J. Synth. Chem. 2010, 18, 64 (in Chinese). (黄家吉, 贺晓鹏, 董菁, 胡键, 施小新, 合成化学, 2010, 18, 64.)

[31] Mancheño, O. G.; Bolm, C. Org. Lett. 2007, 9, 2591.

[32] Nasrollahzadeh, M.; Bayat, Y.; Habibi, D.; Moshaee, S. Tetrahedron Lett. 2009, 50, 4435.

[33] Qi, G.; Dai, Y. Chin. Chem. Lett. 2010, 21, 1029.

[34] Gowd, M. R. M. B.; Pasha, M. A. J. Chem. Sci. 2011, 123, 75.

[35] Teimouri, A.; Chermahini, A. N. Polyhedron 2011, 30, 2606.

[36] Lasri, J.; Rodríguez, M. J. F.; Guedes da Silva, M. F. C.; Smoleński, P.; Kopylovich, M. N.; Fraústo da Silva, J. J. R.; Pombeiro, A. J. L. J. Organomet. Chem. 2011, 696, 3513.

[37] Khamooshi, F.; Modarresi-Alam, A. R. Chin. Chem. Lett. 2010, 21, 892.

[38] Nasrollahzadeh, M.; Habibi, D.; Shahkarami, Z.; Bayat, Y. Tetrahedron 2009, 65, 10715.

[39] Wang, G.-X.; Sun, B.-P.; Peng, C.-H. Org. Process Res. Dev. 2011, $15,986$.

[40] Sun, H.-B.; Chen, W.-L.; Sun, Y.-H.; Qin, P.; Qi, X. Adv. Mater. Res. 2012, 396 398, 2416.

[41] Pokhodylo, N. T.; Matiychuk, V. S.; Obushak, M. D. Tetrahedron 2008, 64, 1430.

[42] Dighe, S. N.; Jain, K. S.; Srinivasan, K. V. Tetrahedron Lett. 2009,
$50,6139$.

[43] Habibi, D.; Nasrollahzadeha, M.; Kamali, T. A. Green Chem. 2011, 13, 3499.

[44] Polivanova, A. G.; Shkavrov, S. V.; Churakov, A. V.; Lermontov, A. S.; Lermontov, S. A. Tetrahedron Lett. 2010, 51, 4205.

[45] Webster, S. P.; Binniea, M.; McConnell, K. M. M.; Sooy, K.; Ward, P.; Greaney, M. F.; Vinter, A.; Pallin, T. D.; Dyke, H. J.; Gill, M. I. A.; Warner, I.; Seckl, J. R.; Walker, B. R. Bioorg. Med. Chem. Lett. 2010, 20, 3265.

[46] Li, J.; Stephanie, Y.; Tao, S.-Y.; Wang, H.-X.; Li, J. J.; Swartz, S.; Musial, C.; Hernandez, A. A.; Flynn, N.; Murphy, B. J.; Beehler, B.; Dickinson, K. E.; Giupponi, L.; Grover, G.; Seethala, R.; Sleph, P.; Slusarchyk, D.; Yan, M.-J.; Humphreys, W. G.; Zhang, H.-J.; Ewing, W. R.; Robl, J. A.; Gordon, D.; Tino, J. A. Bioorg. Med. Chem. Lett. 2008, 18, 1825.

[47] El Kaim, L.; Grimaud, L.; Patil, P. Org. Lett. 2011, 13, 1261.

[48] Saha, B.; Sharma, S.; Sawant, D.; Kundu, B. Tetrahedron 2008, 64, 8676.

[49] Polivanova, A. G.; Shkavrov, S. V.; Churakov, A. V.; Lermontov, A. S.; Lermontov, S. A. Tetrahedron Lett. 2010, 51, 4205.

[50] Pokhodylo, N. T.; Matiychuk, V. S.; Obushak, M. D. Tetrahedron 2008, 64, 1430.

[51] Wu, T.-Z.; Liu, X.-H.; Zhang, F.-L.; Xie, M.-H. Acta Pharm. Sin. 2006, 41,537 (in Chinese).

(吴泰志, 刘晓华, 张福利, 谢美华, 药学学报, 2006, 41, 537.)

[52] Zhou, C.-H.; Zhang, F.-F.; Gan, L.-L.; Zhang, Y.-Y.; Geng, R.-X. Sci. China, Ser. B: Chem. 2009, 39, 208 (in Chinese)

(周成合, 张飞飞, 甘淋玲, 张奕奕, 耿蓉霞, 中国科学 $\mathrm{B}$ 辑: 化 学, 2009, 39, 208.)

[53] Zhou, C.-H.; Gan, L.-L.; Zhang, Y.-Y.; Zhang, F.-F.; Wang, G.-Z.; Jin, L.; Geng, R.-X. Sci. China, Ser. B: Chem. 2009, 52, 415.

[54] Zhou, C.-H.; Zhang, Y.-Y.; Yan, C.-Y.; Wan, K.; Gan, L.-L.; Shi, Y. Anti-Cancer Agents Med. Chem. 2010, 10, 371.

[55] Chang, J.-J.; Wang, Y.; Zhang, H.-Z.; Zhou, C.-H.; Geng, R.-X.; Ji, Q.-G. Chem. J. Chin. Univ. 2011, 32, 1970 (in Chinese).

(常娟娟，王艳，张慧珍，周成合，耿蓉霞，吉庆刚，高等学校化 学学报, 2011, 32, 1970.)

[56] Chawla, G.; Bansal, A. K. Eur. J. Pharm. Sci. 2007, 32, 45.

[57] Hirlekar, R. S.; Sonawane, S. N.; Kadam, V. J. AAPS PharmSciTech 2009, 10, 858.

[58] Wu, J.-H.; Wang, Q.-J.; Guo, J.-Y.; Hu, Z.-Y.; Yin, Z.-Y.; Xu, J.-Y.; Wu, X.-M. Eur. J. Pharmacol. 2008, 589, 220.

[59] Arhancet, G. B.; Woodard, S. S.; Iyanar, K.; Case, B. L.; Woerndle, R.; Dietz, J. D.; Garland, D. J.; Collins, J. T.; Payne, M. A.; Blinn, J. R.; Pomposiello, S. I.; Hu, X.; Heron, M. I.; Huang, H.-C.; Lee, L. F. J. Med. Chem. 2010, 53, 5970.

[60] Gagnon, A.; Landry, S.; Coulombe, R.; Jakalian, A.; Guse, I.; Thavonekham, B.; Bonneau, P. R.; Yoakim, C.; Simoneau, B. Bioorg. Med. Chem. Lett. 2009, 19, 1199.

[61] Muraglia, E.; Kinzel, O. D.; Laufer, R.; Miller, M. D.; Moyer, G.; Munshi, V.; Orvieto, F.; Palumbi, M. C.; Pescatore, G.; Rowley, M.; Williams, P. D.; Summa, V. Bioorg. Med. Chem. Lett. 2006, $16,2748$.

[62] O'Meara, J. A.; Jakalian, A.; LaPlante, S.; Bonneau, P. R.; Coulombe, R.; Faucher, A. M.; Guse, I.; Landry, S.; Racine, J.; Simoneau, B.; Thavonekham, B.; Yoakim, C. Bioorg. Med. Chem. Lett. 2007, 17, 3362.

[63] Zhan, P.; Liu, H.-B.; Liu, X.-Y.; Wang, Y.; Pannecouque, C.; Witvrouw, M.; De Clercq, E. Med. Chem. Res. 2010, 19, 652.

[64] Crosby, D. C.; Lei, X.-Y.; Gibbs, C. G.; McDougall, B. R.; Robinson, W. E.; Reinecke, M. G. J. Med. Chem. 2010, 53, 8161.

[65] Bosch, L.; Delelis, O.; Subra, F.; Deprez, E.; Witvrow, M.; 
Vilarrasa, J. Tetrahedron Lett. 2012, 53, 514.

[66] Yan, S.-Q.; Larson, G.; Wu, J. Z.; Appleby, T.; Ding, Y.-L.; Hamatake, R.; Hong, Z.; Yao, N. Bioorg. Med. Chem. Lett. 2007, 17, 63.

[67] Ronn, R.; Gossas, T.; Sabnis, Y. A.; Daoud, H.; Aakerblom, E.; Danielson, U. H.; Sandstrom, A. Bioorg. Med. Chem. 2007, 15, 4057.

[68] Zarubaev, V. V.; Golod, E. L.; Anfimov, P. M.; Shtro, A. A.; Saraev, V. V.; Gavrilov, A. S.; Logvinov, A. V.; Kiselev, O. I. Bioorg. Med. Chem. 2010, 18, 839.

[69] Anacona, J. R.; Osorio, I. Transition Met. Chem. 2008, 33, 517.

[70] Pochini, L.; Galluccio, M.; Scumaci, D.; Giangregorio, N.; Tonazzi, A.; Palmieri, F.; Indiveri, C. Chem. Biol. Interact. 2008, 173, 187.

[71] Lee, C.-H.; Liu, J.-W.; Li, C.-C.; Chien, C.-C.; Tang, Y.-F.; Su, L.-H. Antimicrob. Agents Chemother. 2011, 55, 4058.

[72] Yildirir, Y.; Us, M. F.; Colak, N.; Ozkan, H.; Yavuz, S.; Disli, A.; Ozturk, S.; Turker, L. Med. Chem. Res. 2009, 18, 91.

[73] Shreaz, S.; Wani, M. Y.; Ahmad, S. R.; Ahmad, S. I.; Bhatia, R.; Athar, F.; Nikhat, M.; Khan, L. A. Eur. J. Med. Chem. 2012, 48, 363.

[74] Diwakar, S. D.; Bhagwat, S. S.; Shingare, M. S.; Gill, C. H. Bioorg. Med. Chem. Lett. 2008, 18, 4678.

[75] El-Sayed, W. A.; Abdel Megeid, R. E.; Abbas, H.-A. S. Arch. Pharm. Res. 2011, 34, 1085.

[76] Navidpour, L.; Amini, M.; Shafaroodi, H.; Abdi, K.; Ghahremani, M. H.; Dehpourd, A. R.; Shafiee, A. Bioorg. Med. Chem. Lett. 2006, 16, 4483 .

[77] Al-Hourani, B. J.; Sharma, S. K.; Mane, J. Y.; Tuszynski, J.; Baracos, V.; Kniess, T.; Suresh, M.; Pietzsch, J.; Wuest, F. Bioorg. Med. Chem. Lett. 2011, 21, 1823.

[78] Kuduk, S. D.; Chang, R. K.; DiPardo, R. M.; Di Marco, C. N.; Murphy, K. L.; Ransom, R. W.; Reiss, D. R.; Tang, C.; Prueksaritanon, T.; Pettibone, D. J.; Bock, M. G. Bioorg. Med. Chem. Lett. 2008, 18, 5107.

[79] Trécant, C.; Dlubala, A.; George, P.; Pichat, P.; Ripoche, I.; Troin, Y. Eur. J. Med. Chem. 2011, 46, 4035.

[80] Carroll, W. A.; Donnelly-Roberts, D.; Jarvis, M. F. Purinergic Signalling 2009, 5, 63.

[81] Ahmed, O. M.; Mohamed, M. A.; Ahmed, R. R.; Ahmed, S. A. Eur. J. Med. Chem. 2009, 44, 3519.

[82] Tang, Y.-D.; Zhang, J.-Q.; Zhang, S.-L.; Geng, R.-X.; Zhou, C.-H. Chin. J. Chem. 2012, 30, 1831.

[83] Nakabayashi, H.; Yawata, O.; Shimizu, K. BMC Cancer 2010, 10, 339.

[84] Hayashi, R.; Jin, X.-M.; Cook, G. R. Bioorg. Med. Chem. Lett. 2007, 17, 6864 .

[85] Doe Santos, L. J.; Alves, R. B.; de Freitas, R. P.; Nierengarten, J.-F.; Magalhas, L. E. F.; Krambrock, K.; Pinheiro, M. V. B. J. Photochem. Photobiol. A: Chem. 2008, 200, 277.

[86] Santos, L. J.; Goncalves, A. S. P.; Krambrock, K.; Pinheiro, M. V. B., Eberlin, M. N.; Vazc, B. G.; de Freitas, R. P.; Alves, R. B. J. Photochem. Photobiol. A: Chem. 2011, 217, 184.

[87] Gundugola, A. S.; Chandra, K. L.; Perchellet, E. M.; Waters, A. M.; Perchellet, J.-P. H.; Rayat, S. Bioorg. Med. Chem. Lett. 2010, 20, 3920 .

[88] Chatzopoulou, M.; Bonovolias, I. D.; Nicolaou, I.; Demopoulos, V. J.; Vizirianakis, I. S.; Tsiftsoglou, A. S. Eur. J. Med. Chem. 2012, $50,75$.

[89] Romagnoli, R.; Baraldi, P. G.; Salvador, M. K.; Preti, D.; Tabrizi, M. A.; Brancale, A.; Fu, X.-H.; Li, J.; Zhang, S.-Z.; Hamel, E.; Bortolozzi, R.; Basso, G.; Viola, G. J. Med. Chem. 2012, 55, 475.

[90] Burgos-Lepley, C. E.; Thompson, L. R.; Kneen, C. O.; Osborne, S.
A.; Bryans, J. S.; Capiris, T.; Suman-Chauhan, N.; Dooley, D. J.; Donovan, C. M.; Field, M. J.; Vartanian, M. G.; Kinsora, J. J.; Lotarski, S. M.; El-Kattan, A.; Walters, K.; Cherukury, M.; Taylor, C. P.; Wustrow, D. J.; Schwarz, J. B. Bioorg. Med. Chem. Lett. 2006, 16, 2333.

[91] Schwarz, J. B.; Colbry, N. L.; Zhu, Z.-J.; Nichelson, B.; Barta, N. S.; Lin, K.; Hudack, R. A.; Gibbons, S. E.; Galatsis, P.; DeOrazio, R. J.; Manning, D. D.; Vartanian, M. G.; Kinsora, J. J.; Lotarski, S. M.; Li, Z.; Dickerson, M. R.; El-Kattan, A.; Thorpe, A. J.; Donevan, S. D.; Taylor, C. P.; Wustrow, D. J. Bioorg. Med. Chem. Lett. 2006, 16, 3559.

[92] Yuan, H.; Silverman, R. B. Bioorg. Med. Chem. Lett. 2007, 17, 1651.

[93] Kimura, T.; Hamada, Y. ; Stochaj, M.; Ikari, H.; Nagamine, A.; Abdel-Rahman, H.; Igawa, N.; Hidaka, K.; Nguyen, J.-T.; Saito, K.; Hayashia, Y.; Kiso, Y. Bioorg. Med. Chem. Lett. 2006, 16, 2380.

[94] Li, J.-J.; Wang, H.-X.; Li, J.; Qu, F.-C.; Swartz, S. G.; Hernandez, A. S.; Biller, S. A.; Robl, J. A.; Tino, J. A.; Slusarchyk, D.; Seethala, R.; Sleph, P.; Yan, M.-J.; Grover, G.; Flynn, N.; Murphy, B. J.; Gordon, D. Bioorg. Med. Chem. Lett. 2008, 18, 2536.

[95] Hernández, A. S.; Cheng, P. T. W.; Musial, C. M.; Swartz, S. G.; George, R. J.; Grover, G.; Slusarchyk, D. R.; Seethala, K.; Smith, M.; Dickinson, K.; Giupponi, L.; Longhi, D. A.; Flynn, N.; Murphy, B. J.; Gordon, D. A.; Biller, S. A.; Robla, J. A.; Tinoa, J. A. Bioorg. Med. Chem. Lett. 2007, 17, 5928.

[96] Hernández, A. S.; Swartz, S. G.; Slusarchyk, D.; Yan, M.-J.; Seethala, K.; Slephb, P.; Grover, G.; Dickinson, K.; Giupponi, L.; Harper, T. W.; Humphreys, W. G.; Longhi, D. A.; Flynn, N.; Murphy, B. J.; Gordon, D. A.; Biller, S. A.; Robl, J. A.; Tino, J. A. Bioorg. Med. Chem. Lett. 2008, 18, 2067.

[97] Sreejith, P.; Beyo, R. S.; Divya, L.; Vijayasree, A. S.; Manju, M.; Oommen, O. V. Indian J. Biochem. Biophys. 2007, 44, 164.

[98] Mohareb, R. M.; Ahmed, H. H.; Elmegeed, G. A.; Abd-Elhalim, M. M.; Shafic, R. W. Bioorg. Med. Chem. 2011, 19, 2966.

[99] Koufaki, M.; Kiziridi, C.; Nikoloudaki, F.; Alexis, M. N. Bioorg. Med. Chem. Lett. 2007, 17, 4223.

[100] Figueiredo, J. A.; Ismael, M. I.; Pinheiro, J. M.; Silva, A. M. S.; Justino, J.; Silva, F. V. M.; Goulart, M.; Mira, D.; Araújo, M. E. M.; Campoy, R.; Rauter, A. P. Carbohydr. Res. 2012, 347, 47.

[101] Semple, G.; Skinner, P. J.; Gharbaoui, T.; Shin, Y.-J.; Jung, J.-K.; Cherrier, M. C.; Webb, P. J.; Tamura, S. Y.; Boatman, P. D.; Sage, C. R.; Schrader, T. O.; Chen, R.; Colletti, S. L.; Tata, J. R.; Waters, M. G.; Cheng, K.; Taggart, A. K.; Cai, T.-Q.; Carballo-Jane, E.; Behan, D. P.; Connolly, D. T.; Richman, J. G. J. Med. Chem. 2008, 51,5101 .

[102] Boatman, P. D.; Schrade, T. O.; Kasem, M.; Johnson, B. R.; Skinner, P. J.; Jung, J. K.; Xu, J.; Cherrier, M. C.; Webb, P. J.; Semple, G.; Sage, C. R.; Knudsen, J.; Chen, R.-P.; Taggart, A. K.; Carballo-Jane, E.; Richman, J. G. Bioorg. Med. Chem. Lett. 2010, 20, 2797.

[103] Eary, C. T.; Jones, Z. S.; Groneberg, R. D.; Burgess, L. E.; Mareska, D. A.; Drew, M. D.; Blake, J. F.; Laird, E. R.; Balachari, D.; Sullivan, M. O.; Allen, A.; Marsh, V. Bioorg. Med. Chem. Lett. 2007, 17, 2608.

[104] Pegklidou, K.; Koukoulitsa, C.; Nicolaou, I.; Demopoulos, V. J. Bioorg. Med. Chem. 2010, 18, 2107.

[105] Wan, Z.-K.; Follows, B.; Kirincich, S.; Wilson, D.; Binnun, E.; Xu, W.-X.; Joseph-McCarthy, D.; Wu, J.-J.; Smith, M.; Zhang, Y.-L.; Tam, M.; Erbe, D.; Tam, S.; Saiah, E.; Lee, J. Bioorg. Med. Chem. Lett. 2007, 17, 2913.

[106] Oballa, R. M.; Belair, L.; Black, W. C.; Bleasby, K; Chan, C. C.; Desroches, C.; Du, X.; Gordon, R.; Guay, J.; Guiral, S.; Hafey, M. 
J.; Hamelin, E.; Huang, Z.; Kennedy, B.; Lachance, N.; Landry, F.; Li, C. S.; Mancini, J.; Normandin, D.; Pocai, A.; Powell, D. A.; Ramtohul, Y. K.; Skorey, K.; Sørensen, D.; Sturkenboom, W.; Styhler, A.; Waddleton, D. M.; Wang, H.; Wong, S.; Xu, L.; Zhang, L. J. Med. Chem. 2011, 54, 5082.

[107] Lachance, N.; Gareau, Y.; Guiral, S.; Huang, Z.; Isabel, E.; Leclerc, J. P.; Leger, S.; Martins, E.; Nadeau, C.; Oballa, R. M. Bioorg. Med. Chem. Lett. 2012, 22, 980.

[108] Lachance, N.; Guiral, S.; Huang, Z.; Leclerc, J. P.; Li, C.- S.; Oballa, R. M.; Ramtohul, Y. K.; Wang, H.; Wu, J.; Zhang, L. Bioorg. Med. Chem. Lett. 2012, 22, 623.

[109] Pinna, M. V.; Zema, M.; Gessa, C.; Pusino, A. J. Agric. Food Chem. 2007, 55, 6659.

[110] Feng, G.-R.; Huo, A.-X.; Zhang, S.-X.; Wang, H.-R.; Wang, H.-Q. J. Nanjing Normal Univ. (Nat. Sci. Ed.) 2007, 30, 71 (in Chinese). (冯桂荣, 霍爱新, 李淑贤, 张会茹, 王虎群, 南京师范大学学 报, 2007, 30, 71.)

[111] Wang, B.-L.; Li, Z.-M.; Li, Y.-H.; Wang, S.-H. Chem. J. Chin. Univ. 2008, 29, 90 (in Chinese).

(王宝雷, 李正名, 李永红, 王素华, 高等学校化学学报, 2008, 29, 90.)

[112] Luo, Y.-P.; Gong, Q.; Chen, Q.; Yang, G.-F. Chin. J. Org. Chem. 2008, 28, 1561 (in Chinese). (骆炎平, 龚青, 陈琼, 杨光富, 有机化学, 2008, 28, 1561.)

[113] Wei, T.-B.; Li, W.; Xu, R.; Zhang, Y.-M.; Gao, L.-M. Chin. J. Org. Chem. 2008, 28, 99 (in Chinese). (魏太保, 李伟, 徐蓉, 张有明, 高黎明, 有机化学, 2008, 28, 99.)

[114] Li, W.; Zhang, Y.-M.; Wei, T.-B.; Gao, L.-M. Chin. J. Org. Chem. 2008, 28, 454 (in Chinese). (李伟, 张有明, 魏太保, 高黎明, 有机化学, 2008, 28, 454.)

[115] Luo, Y.-P.; Yang, G.-F. J. Heterocycl. Chem. 2007, 44, 937.

[116] Luo, Y.-P.; Yang, G.-F. Bioorg. Med. Chem. 2007, 15, 1716.

[117] Xie, Y.- F.; Yu, Y.; Fan, Z.-J.; Ma, L.; Mi, N.; Tang, L.-F. Appl. Organomet. Chem. 2010, 24, 1.

[118] Zhang, X.-W.; Zhu, W.-H.; Wei, T.; Zhang, C.-C.; Xiao, H.-M. J. Phys. Chem. C. 2010, 114, 13142.

[119] Qi, S.-Y.; Zhang, T.-L.; Yang, L.; Zhang, J.-G.; Zang, Y.; Cui, Y. Chin. J. Energ. Mater. 2009, 17, 486 (in Chinese). (齐书元, 张同来, 杨利, 张建国, 蔵艳, 崔燕, 含能材料, 2009, 17, 486.)

[120] Huang, H.-F.; Meng, Z.-H.; Zhou, Z.-M.; Gao, H.-X.; Zhang, J.; Wu, Y.-K. Prog. Chem. 2009, 21, 152 (in Chinese). (黄海丰, 孟子晖, 周智明, 高海翔, 章军, 吴玉凯, 化学进展, 2009, 21, 152.)

[121] Li, Z.-M.; Zhang, J.-G.; Liu, J.-W.; Zhai, J.-X.; Zhang, T.-L. J. Solid Rocket Technol. 2011, 34, 79 (in Chinese). (李志敏, 张建国, 刘俊伟, 翟进贤, 张同来, 杨利, 固体火箭技 术, 2011, 34, 79.)

[122] Liu, X.-J.; Zhang, H.-J.; Lin, Q.-H.; Li, Y.-C.; Li, Y.-Y.; Li, Y.-Y.; Pang, S.-P. Chin. J. Explos. Propellants 2010, 33, 6 (in Chinese). (刘晓建, 张慧娟, 林秋汉, 李玉川, 李亚裕, 庞思平, 火炸药学 报, 2010, 33, 6.)

[123] Jiao, B.-J.; Yan, Z.-J.; Wang, J.; Jin, X. Appl. Chem. Ind. 2009, 38, 150 (in Chinese).

(焦宝娟, 晏志军, 王静, 金金鉒, 应用化工, 2009, 38, 150.)

[124] Cheng, T.-L.; Ma, F.-E.; Zhang, Y.-F.; Zhu, Y.-H.; Chen, L.-K.; Yang, B. Chin. J. Energ. Mater. 2007, 15, 511 (in Chinese). (盛涤伦, 马凤娥, 张裕峰, 朱雅红, 陈利鬼, 扬斌, 含能材料, 2007, 15, 511.)

[125] Chen, H.-Y.; Zhang, T.-L.; Zhang, J.-G. Chin. J. Struct. Chem. 2012, 23, 153 .
[126] Cui, Y.; Zhang, T.-L.; Zhang, J.-G.; Yang, L.; Hu, X.-C.; Zhang, J. J. Mol. Struct. 2008, 889, 177.

[127] Xia, Z.-Q.; Chen, S.-P.; Wei, Q.; Qiao, C.-F. J. Solid State Chem. 2011, 184, 1777.

[128] Çelik, S. Ü.; Akbey, Ü.; Bozkurt, A.; Graf, R.; Spiess, H. W. Macrom. Chem. Phys. 2008, 209, 593.

[129] Akbey, Ü.; Graf, R. Peng, Y.-G.; Chu, P.-P. Spiess, H. W. Polym. J. Sci., Part B 2009, 47, 138.

[130] Pu, H.-T.; Sheng, Y. React. Funct. Polym. 2006, 66, 856.

[131] Pu, H.-T.; Wu, J.; Wan, D.-C.; Chang, Z.-H. J. Membr. Sci. 2008, $322,392$.

[132] Celik, S. Ü.; Coşgun, S.; Akbey, Ü.; Bozkurt, A. Ionics 2012, 18, 101.

[133] Celik, S. Ü.; Bozkurt, A. Solid State Ionics 2011, 199-200, 1.

[134] Den, S.; Celik, S. Ü.; Bozkurt, A. Electrochim. Acta 2010, 55, 8498.

[135] Sen, U.; Celik, S. Ü.; Ata, A.; Bozkurt, A. Int. J. Hydrogen Energy 2008, 33, 2808.

[136] Tang, Y.-Z.; Tan, Y.-H.; Liu, D.-L.; Luo, X.-P.; Xie, X.-B.; Liu, Z.-X.; Ge, Z.-T. Inorg. Chim. Acta 2009, 362, 1969.

[137] Shi, L.-F.; Li, B.; Yue, S.-M.; Fan, D. Sens. Actuators, B 2009, 137, 386.

[138] He, X.; Zhang, J.; Wu, X.-Y.; Lu, C.-Z. Inorg. Chim. Acta 2010, 363, 1727.

[139] Tang, Y.-M.; Yang, W.-Z.; Yin, X.-S.; Liu, Y.; Wan, R.; Wang, J.-T. Mater. Chem. Phys. 2009, 116, 479.

[140] Liu, P.-J.; Fang, X.; Tang, Y.-M.; Sun, C.-N.; Yao, C. Mater. Sci. Appl. 2011, 2, 1268.

[141] Antonijevic, M. M.; Milic, S. M.; Petrovic, M. B. Corros. Sci. 2009, 51, 1228.

[142] Mihit, M.; Laarej, K.; Abou El Makarim, H.; Bazzi, L.; Salghi, R.; Hammouti, B. Arabian J. Chem. 2010, 3, 55.

[143] Sherif, E.-S. M. Int. J. Electrochem. Sci. 2012, 7, 1482.

[144] Sherif, E.-S. M.; Erasmus, R. M.; Comins, J. D. J. Appl. Electrochem. 2009, 39, 83.

[145] Sherif, E.-S. M.; Erasmus, R. M.; Comins, J. D. Corros. Sci. 2008, $50,3439$.

[146] Zhang, X.-M.; Liu, R.-Q. Mater. Prot. 2009, 42, 24 (in Chinese). (张雪梅, 刘瑞泉, 材料保护, 2009, 42, 24.)

[147] Mihit, M.; El Issami, S.; Bouklah, M.; Bazzi, L.; Hammouti, B.; Ait Addi, E.; Salghi, R.; Kertit, S. Appl. Surf. Sci. 2006, 252, 2389.

[148] Khaleda, K. F.; Al-Qahtani, M. M. Mater. Chem. Phys. 2009, 113, 150.

[149] Pang, X.-H.; Ran, X.-B.; Xie, J.-D.; Zhang, S.-T.; Hou, B.-R. Acta Chim. Sinica 2009, 67, 2279 (in Chinese).

(庞雪辉, 由祥滨, 解建东, 张胜涛, 侯保荣, 化学学报, 2009, 67, 2279.)

[150] Sherif, E.-S. M. Mater. Chem. Phys. 2011, 129, 961.

[151] Pihko, P. M.; Majander, I.; Erkkilä, A. Top. Curr. Chem. 2010, 291, 29.

[152] Arnó, M.; Zaragozá, R. J.; Domingo, L. R. Tetrahedron 2007, 18, 157.

[153] Hartikka, A.; Arvidsson, P. I. J. Org. Chem. 2007, 72, 5874.

[154] Tong, S. T.; Brimble, M. A.; Barker, D. Tetrahedron 2009, 65, 4801.

[155] Funabiki, K.; Itoh, Y.; Kubota, Y.; Matsui, M. J. Org. Chem. 2011, 76,3545 .

[156] Kim, S. G.; Park, T. H. Tetrahedron Lett. 2006, 47, 9067.

[157] He, Y.; Cai, C. Transition Met. Chem. 2011, 36, 113.

[158] He, Y.; Cai, C. Catal. Lett. 2010, 140, 153. 